\title{
Microwave-assisted $\mathrm{TiO}_{2}$ : anatase formation on cotton and viscose fabric surfaces
}

\author{
Patrycja Giesz • Grzegorz Celichowski • Dorota Puchowicz • \\ Irena Kamińska • Jarosław Grobelny • Damian Batory • \\ Małgorzata Cieślak
}

Received: 4 February 2016/Accepted: 20 March 2016/Published online: 28 March 2016

(C) The Author(s) 2016. This article is published with open access at Springerlink.com

\begin{abstract}
The method of $\mathrm{TiO}_{2}$-anatase film preparation on cotton and viscose fabric surfaces using the sol-gel process and microwave treatment is presented. Microwave treatment was used to change the amorphous $\mathrm{TiO}_{2}$ form to anatase directly on the fabrics. The influence of microwave treatment conditions on the obtainable polymorphic form of $\mathrm{TiO}_{2}$ was examined. Fabrics were pretreated with low-temperature air plasma (30 min). The root mean square height in the selected area increased from 44 to $166 \mathrm{~nm}$ (cotton) and from 9 to $112 \mathrm{~nm}$ (viscose). Infrared analysis showed the new band at 1748 and $1732 \mathrm{~cm}^{-1}$ corresponding to $\mathrm{C}=\mathrm{O}$ stretching for plasma-treated cotton and viscose textiles, respectively. The plasma pretreatment also improved the wetting properties by $\mathrm{TiO}_{2}$ sol and increased the surface free energy of fabrics. $\mathrm{TiO}_{2}$ film thickness was $180 \mathrm{~nm}(12 \% \mathrm{wg}$. Ti)
\end{abstract}

P. Giesz · D. Puchowicz · I. Kamińska - M. Cieślak ( $₫)$ Scientific Department of Unconventional Technologies and Textiles, Textile Research Institute, 5/15 Brzezińska St., 92-103 Lodz, Poland

e-mail: cieslakm@iw.lodz.pl

P. Giesz · G. Celichowski · J. Grobelny

Department of Materials Technology and Chemistry, Faculty of Chemistry, University of Lodz, 163 Pomorska St., 90-236 Lodz, Poland

D. Batory

Institute Materials Science and Engineering, Lodz University of Technology, 1/15 Stefanowskiego St., 90-924 Lodz, Poland and $140 \mathrm{~nm}$ (3\%wg. Ti) for cotton and viscose, respectively. $\mathrm{TiO}_{2}$-modified cotton reduced the nicotine concentration three times more and $\mathrm{TiO}_{2}$-modified viscose was two times higher under sunlight compared to raw fabrics. No changes in strength were observed for $\mathrm{TiO}_{2}$-modified cotton, while the strength of $\mathrm{TiO}_{2}$-modified viscose decreased about $45 \%$. No effect of UV irradiation on cotton and a slight reduction of the strength of raw viscose $(7 \%)$ and $\mathrm{TiO}_{2}$-modified viscose $(16 \%)$ were observed. The $\mathrm{Ti}$ contents after washing decreased from 12 to $11 \%$ (cotton) and from 3 to $2.6 \%$ (viscose). The presented method allows obtaining $\mathrm{TiO}_{2}$ film-anatase on the cotton and viscose fabrics, but its total effectiveness is better for cotton fabrics.

Keywords Microwave $\cdot \mathrm{TiO}_{2} \cdot$ Sol-gel $\cdot$ Plasma . Cotton $\cdot$ Viscose

\section{Introduction}

Titanium dioxide $\left(\mathrm{TiO}_{2}\right)$, especially in the anatase phase applied to the modification of textile materials, provides new properties such as photocatalytic, selfcleaning, bioactive, UV protective, superhydrophilic, antibacterial, flame retardant, etc. (Radetic 2013; Karimi et al. 2014; Morawski et al. 2013; Qi et al. 2006; Ibrahim et al. 2010; Karimi et al. 2010, Abidi et al. 2009). There are many methods to modify 
materials with $\mathrm{TiO}_{2}$; some of them require post-heat treatment to induce crystallization, e.g., the sol-gel method. At low temperature, it can be distinguished hydrothermally (Zhang et al. 2012) or using the sonochemical method (Behzadnia et al. 2014a, b). Both methods allow obtaining $\mathrm{TiO}_{2}$ film in crystalline form. In the hydrothermal method, a long aging period is necessary to obtain the crystalline $\mathrm{TiO}_{2}$ form. The sonochemical method was used to produce multifunctional wool fabric using titanium isopropoxide or butoxide in acidic media. Another method is the application of a $\mathrm{TiO}_{2}$ dispersion or Ag-doped $\mathrm{TiO}_{2}$ in the anatase form to the modification of the fibers and wovens surface (Cieslak et al. 2009). The most popular, fast, effective and easy method of producing $\mathrm{TiO}_{2}$ thin films is a solgel method, but one of the disadvantages is the annealing post-treatment at high temperature (near $500{ }^{\circ} \mathrm{C}$ ) to transform amorphous $\mathrm{TiO}_{2}$ to the anatase form (Cieslak et al. 2015; Tung and Daoud 2011; Kadziola et al. 2014). Such treatment limits the ability to create films on textile substrates with low thermal resistance, such as cotton, viscose, wool, polypropylene, polyamide, polyester fibers, etc. (Liu et al. 2007). The microwave treatment is one of the methods in which $\mathrm{TiO}_{2}$ in anatase form can be enhanced at lower temperature (below $200{ }^{\circ} \mathrm{C}$ ). The application of microwave treatment may be useful for the modification of low-thermal-resistance textile materials. Some approaches using microwave treatment to obtain crystalline $\mathrm{TiO}_{2}$ have been reported (Liu et al. 2007; Wilson et al. 2002; Vigil et al. 2001). Liuxue et al. (2007) obtained $\mathrm{TiO}_{2}$ anatase on cotton fibers prepared via a microwaveassisted liquid-phase process with hexafluorotitanate as precursor. Microwaving improved the hydrolysis of the precursor and led to highly crystalline anatase at low temperature. Similar studies were carried out by Peiro et al. (2001), but the $\mathrm{TiO}_{2}$ anatase film was deposited on glass substrates and silicon wafers. Li et al. (2010) prepared silvermodified $\mathrm{TiO}_{2}$ via a microwave-assisted method. All papers presented the process of $\mathrm{TiO}_{2}$ preparation and/or deposition on film during the microwave treatment. In this study, we show another method in which fibers with $\mathrm{TiO}_{2}$ film (prepared using the sol-gel technique earlier) were only treated with microwaves to transform $\mathrm{TiO}_{2}$ to the anatase form.

\section{Materials}

To prepare $\mathrm{TiO}_{2}$ sol, titanium (IV) isopropoxide Ti(OC3H7)4 (TTIP, $97 \%$, Aldrich) as a Ti precursor, isopropanol (99.5\%, POCH S.A.) and hydrochloric acid (Chempur) were used. $\mathrm{TiO}_{2}$ sol was applied to plain-woven cellulose fabrics whose characteristics are given in Table 1.

$\mathrm{TiO}_{2}$ film was also applied on silicon ( $\mathrm{Si}$ ) wafer 100 (Cemat Silicon S.A.) with a thickness of 320-380 $\mu \mathrm{m}$ as a reference substrate material.

\section{Methods}

$\mathrm{TiO}_{2}$ thin film preparation

Titanium dioxide was prepared based on a sol-gel technique using $\mathrm{Ti}$ - titanium tetraisopropoxide as precursor. To the solution containing $1.2 \mathrm{~g}(0.00422 \mathrm{~mol})$ TTIP in $13.2 \mathrm{~g}(0.22 \mathrm{~mol})$ of isopropanol, $0.04 \mathrm{~g}$ $(0.0011 \mathrm{~mol})$ of hydrochloric acid $(\mathrm{HCl} 2 \mathrm{~mol} / \mathrm{l})$ was added dropwise. The prepared sol was stirred $30 \mathrm{~min}$ before deposition on the fabric samples and $\mathrm{Si}$ wafers. The surfaces of cotton and viscose fabrics were pretreated in low-temperature air plasma ( $45 \mathrm{~W}$, 15.26 MHz, Zepto) for $30 \mathrm{~min}$. $\mathrm{TiO}_{2}$ sol was applied on the pretreated substrates by dip-coating technique using an NIMA dip coater (Technology LB, UK) with a constant rate of $25 \mathrm{~mm} / \mathrm{min}$. After the sol deposition, fabrics and $\mathrm{Si}$ wafers were dried at room temperature for $48 \mathrm{~h}$. Next, the samples were placed in vessels filled with distilled water and treated with microwaves (MWs) using an Anton Paar Synthos microwave reactor. After the MW treatment, the samples were dried at room temperature. Different MW treatment conditions were tested (various powers and heating times), and the results of two selected conditions are presented in this article (MW power and heating time $650 \mathrm{~W}, 15 \mathrm{~min}$ at $T=180{ }^{\circ} \mathrm{C}$ and $500 \mathrm{~W}, 10 \mathrm{~min}$ at $T=110^{\circ} \mathrm{C}$ ) (Fig. 1). MW treatment was only used for conversion of the $\mathrm{TiO}_{2}$ amorphous form deposited on the fabric surface to $\mathrm{TiO}_{2}$ anatase.

\section{Characterization}

A thermogravimetric analysis (TGA) of viscose and cotton fabrics was carried out using a TG 209F1 Libra analyzer (Netzsch, Germany) with a heating rate of 
Table 1 Characteristics of the studied fabrics

\begin{tabular}{lllll}
\hline Fabric composition (\%) & Weave & Mass per unit area $\left(\mathrm{g} / \mathrm{m}^{2}\right)$ & \multicolumn{2}{l}{ Pick and end densities $(1 / \mathrm{cm})$} \\
\cline { 4 - 5 } & & & Warp & Weft \\
\hline Cotton 100 & Plain & 108 & 43 & 32 \\
Viscose 100 & Plain & 104 & 45 & 25 \\
\hline
\end{tabular}

\begin{tabular}{|c|c|c|}
\hline$\left(\mathrm{C}_{3} \mathrm{H}_{7} \mathrm{O}\right)_{4} \mathrm{Ti}$ & & \\
\hline $\mathrm{C}_{3} \mathrm{H}_{7} \mathrm{OH}$ & \multirow{5}{*}{$\begin{array}{c}\text { Dip-coating of } \\
\text { pre-treated fabrics } \\
\text { and Si wafer } \\
\text { Drying at room temperature }\end{array}$} & \multirow{5}{*}{$\begin{array}{l}\text { Microwave treatment of } \mathrm{TiO}_{2} \text { modified } \\
\text { fabrics in distilled water (for the conversion } \\
\text { of amorphous } \mathrm{TiO}_{2} \text { to anatase form) } \\
650 \mathrm{~W}, 15 \mathrm{~min} \\
500 \mathrm{~W}, 10 \mathrm{~min} \\
\text { Drying at room temperature }\end{array}$} \\
\hline $\begin{array}{c}\mathrm{HCl} \\
\text { Stirring }\end{array}$ & & \\
\hline & & \\
\hline Plasma-treated & & \\
\hline $\begin{array}{l}\text { fabrics } \\
\text { and Si wafer }\end{array}$ & & \\
\hline
\end{tabular}

Fig. 1 Flowchart of thin $\mathrm{TiO}_{2}$ layer preparation on fabrics and $\mathrm{Si}$ wafers

$10{ }^{\circ} \mathrm{C} \min ^{-1}$ under a nitrogen flow rate of $20 \mathrm{ml} \mathrm{min}{ }^{-1}$ over the range of $30-700{ }^{\circ} \mathrm{C}$. The samples $(4.0 \pm 2 \mathrm{mg})$ were tested in a ceramic crucible. The initial $\left(T_{\text {Onset }}\right)$ and final $\left(T_{\text {End }}\right)$ temperature of degradation, temperature at peak maximum degradation ( $T_{\text {Max }}$ Peak $)$ and loss of mass were evaluated. Fabrics were pretreated in low-temperature air plasma (50 W, Zepto) for $30 \mathrm{~min}$. The surface morphologies of fabrics and Si wafers were studied with a scanning electron microscope (SEM) (Nova NanoSEM 450, FEI, USA). The thickness of the $\mathrm{TiO}_{2}$ coating on the fiber surfaces was evaluated on the basis the SEM images of fiber cross sections. The elemental composition analysis and maps of Ti distribution were performed with an X-ray microanalyzer (INCA Energy EDS, Oxford Instruments Analytical, UK) connected to a Vega 3 SEM (Tescan, Czech Republic). The 3D SEM images were prepared using Alicona MeX software connected to a Vega 3 SEM. FTIR analysis of textiles before and after plasma treatment using the Thermo Scientific Nicolet iS50 FT-IR equipped with a Golden Gate ATR accessory with 4$\mathrm{cm}^{-1}$ resolution was made. Raman spectra and mapping analyses of modified fabrics were performed using a Raman Renishaw InVia dispersive spectrometer (Renishaw, UK) with infrared $\lambda=785$-nm laser excitation. The phase composition of the examined samples was measured using the X-ray diffraction technique. In the investigation, an Empyrean diffractometer (PANalytical) working in grazing incidence
(GIXRD) mode with Co $\mathrm{K} \alpha(1.78901 \mathrm{~A})$ radiation was used. The incidence angle (omega) was set to $2^{\circ}$. Further data processing was done using the ICDD PDF 4 database and HighScore Plus software. To evaluate the impact of plasma treatment on the surface free energy (SFE) of fabrics and the wettability of fabrics by $\mathrm{TiO}_{2}$ sol, the contact angle was measured using the Drop Shape Analyzer (Krüss GmbH DSA 100, Germany) and three non-reactive standard liquids (droplet size of $5 \mu \mathrm{l})$ : distilled water $\left(\gamma_{1}=72.8\right.$; $\left.\gamma_{1}^{\mathrm{d}}=21.8 ; \quad \gamma_{1}^{\mathrm{p}}=51.0\right)$, diiodomethane $\left(\gamma_{1}=50.8\right.$; $\left.\gamma_{1}^{\mathrm{d}}=48.5 ; \quad \gamma_{\mathrm{p}}^{\mathrm{p}}=2.3\right)$ and formamide $\left(\gamma_{1}=58.0\right.$; $\left.\gamma_{1}^{\mathrm{d}}=39.0 ; \gamma_{\mathrm{p}}^{\mathrm{p}}=19.0\right)$. On the basis of the obtained contact angle values, the SFE was calculated using the Owens-Wendt model (Owens and Wendt 1969; Cieslak et al. 2012). In this model, the SFE is calculated from the geometric mean of dispersion and polar interactions between the solid and liquid, according to Eq. (1):

$$
\begin{aligned}
\gamma_{1}(1+\cos \theta) & =2\left[\left(\gamma_{1}^{\mathrm{d}} \gamma_{\mathrm{s}}^{\mathrm{d}}\right)^{1 / 2}+\left(\gamma_{1}^{\mathrm{d}} \gamma_{\mathrm{s}}^{\mathrm{d}}\right)^{1 / 2}\right] \text { and } \gamma_{\mathrm{s}} \\
& =\gamma_{\mathrm{s}}^{\mathrm{d}}+\gamma_{\mathrm{s}}^{\mathrm{d}}
\end{aligned}
$$

where $\theta$ is the contact angle, and $\gamma_{\mathrm{s}}^{\mathrm{d}}, \gamma_{\mathrm{s}}^{\mathrm{p}}, \gamma_{1}^{\mathrm{d}}$ and $\gamma_{1}^{\mathrm{p}}$ are the dispersion $\left({ }^{\mathrm{d}}\right)$ and polar $\left({ }^{\mathrm{p}}\right)$ components of the surface free energies of the solid $\left(_{\mathrm{s}}\right.$ ) and liquid ( ${ }_{1}$ ), respectively. The reversible work of adhesion (Wa) of the fabric and water was calculated using Dupre's Eq. (2) (Dupre 1869):

$\mathrm{Wa}=\gamma s+\gamma l-\gamma s l$ 
where $\gamma s$ is the surface free energy of the solid, $\gamma s l$ is the solid/liquid interface tension, and $\gamma l$ is the surface free energy of the liquid.

The photocatalytic properties were tested by the decomposition of nicotine adsorbed on cotton and viscose fabrics modified with $\mathrm{TiO}_{2}$-anatase. The testing was performed at $21 \pm 2{ }^{\circ} \mathrm{C}$ on the test stand as previously described (Cieslak et al. 2009; Cieslak et al. 2014). Briefly, ten samples of each fabric type were hung in a chamber $\left(40 \mathrm{dm}^{3}\right)$ and the chamber air was evacuated; $5 \mu$ of nicotine (Fluka 72290, CAS 54-11-5, puriss. p.a. $>99.0 \%$ ) was injected into a $U$ shaped tube placed in the bath warmed up to $250{ }^{\circ} \mathrm{C}$, and nicotine vapor was supplied in a stream of air into the chamber. The chamber was protected from light with a black cover. After $24 \mathrm{~h}$, two samples of each fabric type were removed from the chamber and subjected to chromatographic analysis to assess the initial concentration of nicotine. The rest of the samples were placed on a frame attached to the window and exposed to sunlight. Two sensors (CMP 3 and CUV 4, Kipp and Zonen B.V.) were used to measure the light intensity, which was in the $310-2800 \mathrm{~nm}$ and 305-385 nm range, respectively. Periodically, two samples of each type were taken to determine the nicotine concentration. The total irradiation dose was $405.8 \mathrm{~kJ} / \mathrm{m}^{2}$.

Tensile strength tests before and after modifications of the fabrics and UV irradiation were performed according to standard PN-EN ISO 13934-1:2013-07 using an Instron 3367 machine. The fabrics were UV irradiated (305-385 nm) with the use of a Xenotest Alpha HE apparatus (Atlas) with a total irradiation dose $(P)$ of $5184 \mathrm{~kJ} / \mathrm{m}^{2}$. Five repetitions were carried out for each fabric type, and the average values of the breaking force and breaking elongation were determined.

Washing of the $\mathrm{TiO}_{2}$-modified samples was performed according to standard PN EN ISO 6330:2012, procedure $4 \mathrm{~N}$, method A. The Ti contents of samples before and after washing were evaluated on the basis of the SEM/EDS analysis.

\section{Results and discussion}

On the basis of the thermal analysis (Fig. 2), it was noticed that the thermal decomposition of cotton and viscose started at $320.9^{\circ} \mathrm{C}\left(T_{\text {Onset }}\right)$ and $293.5^{\circ} \mathrm{C}$ $\left(T_{\text {Onset }}\right)$ with the maximum $\left(T_{\text {Max Peak }}\right)$ at 366.0 and
$343.3{ }^{\circ} \mathrm{C}$, respectively. Cotton fabric is thermally stable up to about $320{ }^{\circ} \mathrm{C}$ and viscose fabric up to $293{ }^{\circ} \mathrm{C}$; above these temperatures, degradation of fabrics was observed. Therefore, the experiments were carried out at lower temperatures of 110 and $180{ }^{\circ} \mathrm{C}$.

The nano-roughness of plasma-treated fabric surfaces was higher than that of the untreated fabrics (Figs. 3, 4, 5). An etching effect of plasma treatment and uniform surface structure of both fabrics without any cracks or damages were observed. The 3D SEM pictures (Fig. 5) clearly showed the changes in the surface structure of fibers after plasma treatment. A significant increase in their roughness was observed. The root-mean-square height of the measured area of $64 \mu^{2}$ increased from 44 to $166 \mathrm{~nm}$ and from 9 to $112 \mathrm{~nm}$ for plasma-treated cotton and viscose, respectively (Fig. 5). Such nano-topography changes on the fabric surfaces are also described in the literature (Navaneetha Pandiyaraj and Selvarajan 2008; Shishoo 2007; Mihailovic et al. 2011). The surface development can provide a new pathway for the $\mathrm{TiO}_{2}$ sol and improve its application. According to Mirjalili et al. (2015), corona treatment of cotton improves the adsorption of $\mathrm{TiO}_{2}$ nanoparticles and thus ensures stable properties of materials, e.g., self-cleaning. In addition, $\mathrm{TiO}_{2}$ film on cotton with corona pretreatment is stable even after 50 washing cycles. In the research of Mihailovic et al. (2011), the amount of $\mathrm{TiO}_{2}$ for air RF plasma-pretreated cotton increased about $31 \%$ compared to untreated fabric. Corona discharge/air RF plasma resulted in an increase in the binding efficiency of $\mathrm{TiO}_{2}$ nanoparticles.

The effect of plasma treatment of fabric in the studies differs for each type of fiber. In the case of cotton fibers (Fig. 3), these changes are characteristic of the morphology of the surface layer, including the primary topography (irregularities on the cotton fiber). The higher roughness of cotton allows increasing the surface area and the amount of $\mathrm{TiO}_{2}$ deposition. The viscose fiber texture is very even, also in the longitudinal recesses, but more amorphous viscose causes susceptibility to plasma etching (Fig. 4) (Prysiazhnyi et al. 2013).

The FTIR spectra of untreated and plasma-treated fabrics are demonstrated in Fig. 6. All spectra show characteristic broad bands around 3339, 3340 and $3392 \mathrm{~cm}^{-1}$, which correspond to alcoholic $\mathrm{OH}$ stretching, and bands around $2900 \mathrm{~cm}^{-1}$ and in the region 1455,1430 and $1429 \mathrm{~cm}^{-1}$ due to $\mathrm{CH}_{2}$ 
Fig. 2 TGA analysis of $\mathbf{a}$ cotton and $\mathbf{b}$ viscose fabrics (a) TG $1 \%$

DTG $/(\% / \mathrm{min})$

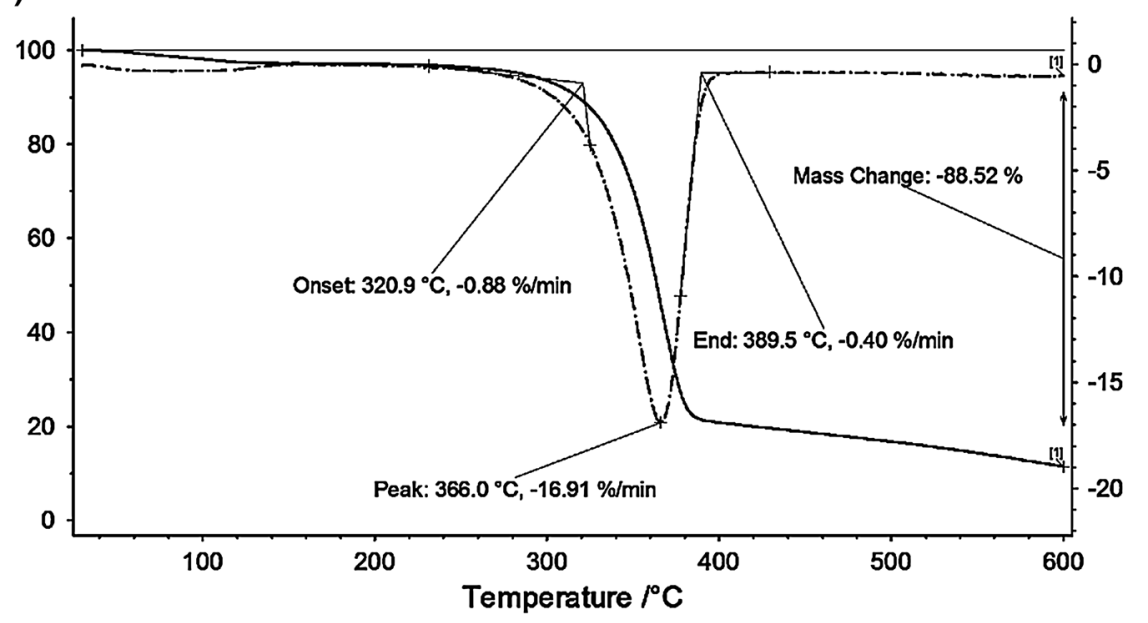

(b) TG $/ \%$

DTG $/(\% / \min )$

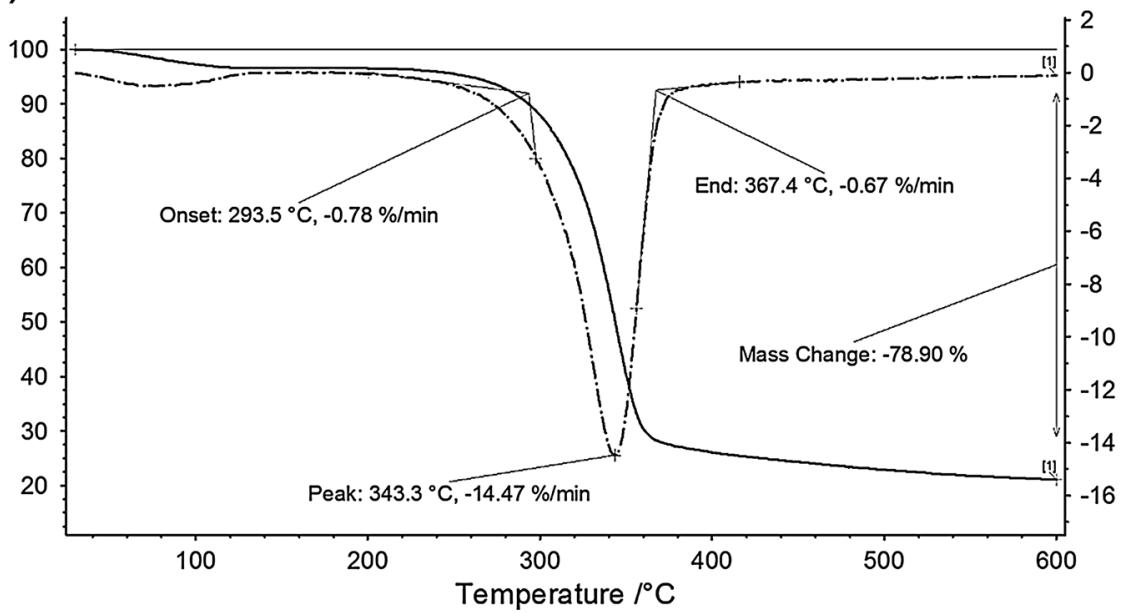

stretching and $\mathrm{CH}_{2}$ bending, respectively. Carboxyl groups were noticed in the viscose and cotton plasmatreated samples with bands at 1732 and $1748 \mathrm{~cm}^{-1}$ (Fig. 6b,d) corresponding to $\mathrm{C}=\mathrm{O}$ stretching. This proves that besides etching (confirmed by SEM analysis), surface oxidation of both fibers by plasma occurs. Also a higher intensity of bands was observed in the $1429-1061 \mathrm{~cm}^{-1}$ range. Bands near $1455-1061 \mathrm{~cm}^{-1}$ correspond to $\mathrm{C}-\mathrm{O}$ stretching and in the range $1200-1400 \mathrm{~cm}^{-1}$ are $\mathrm{O}-\mathrm{H}$ bending bands (Caschera et al. 2014; Ibrahim et al. 2012). Karahan and Özdoan (2008) did not obtain bands around $1740 \mathrm{~cm}^{-1}$ by atmospheric plasma treatment; however, they obtained this band by Ar plasma treatment. The FTIR results clearly show an increase in the intensity band at $3340 \mathrm{~cm}^{-1}$, especially for cotton, which indicates the greater number of $\mathrm{OH}$ groups after 30-min plasma treatment. The more polar $\mathrm{OH}$ groups and the formation of new polar groups such as $\mathrm{C}=\mathrm{O}$ (both of cotton and viscose) after plasma etching cause an increase in the hydrophilicity and the value of the surface free energy and adhesion properties. Similar observations were made by Kiwi and Pulgarin (2010). The increase in polar groups and roughness of the cotton surface during RF plasma treatment improved the effectiveness of the modification of the cotton surface with the nanomodifiers $\mathrm{TiO}_{2}$ and $\mathrm{Ag}$. After the plasma treatment of fabrics, a decrease in the contact angle was observed for all standard liquids. For water, the value of the contact angle decreased from $55^{\circ}$ to $10^{\circ}$ and from $50^{\circ}$ to $7^{\circ}$ for cotton and viscose fabric, respectively (Table 2). The values of SFE for cotton 

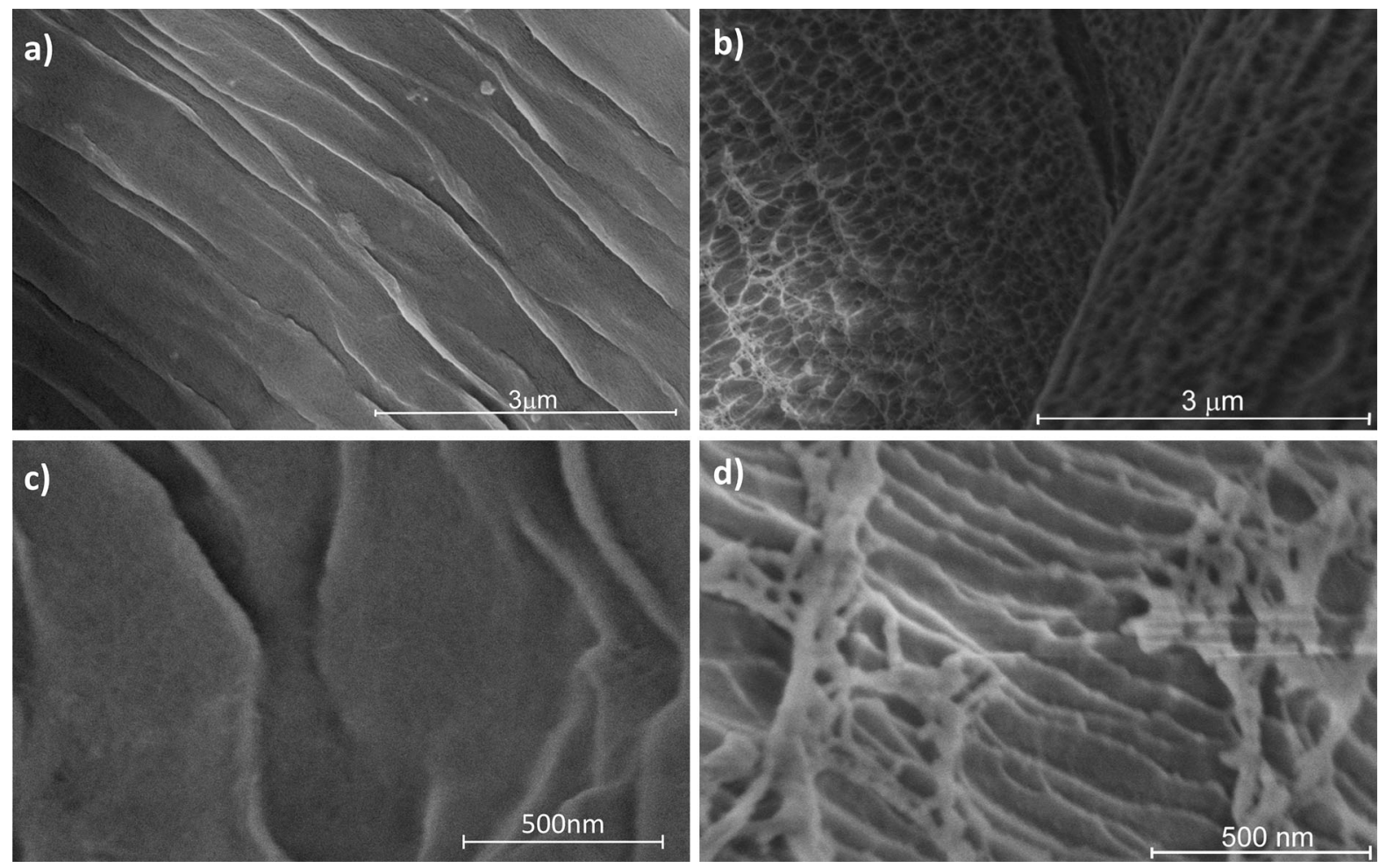

Fig. 3 SEM images of raw cotton (a, $\mathbf{c} \times 30,000$ and $\times 120,000$ magnifications $)$ and 30 -min plasma-treated cotton $(\mathbf{b}, \mathbf{d} \times 30,000$ and $\times 120,000$ magnifications)

and viscose increased by about 26 and $23 \mathrm{~mJ} / \mathrm{m}^{2}$, respectively (Table 2). A larger increase in the polar component was observed for cotton (twofold) than for viscose $(30 \%)$. For the dispersion component, it rose by 25 and $35 \%$ for cotton and viscose, respectively. This was mainly due to the polar groups, such as $\mathrm{C}=\mathrm{O}$, formed on the fabric surfaces. This resulted in an increase of the polar components of SFE and consequently improved the wettability. The $W_{\text {adh }}$ for water increased to $145 \mathrm{~mJ} / \mathrm{m}^{2}$ for both fabrics. The adhesion properties of fabrics were higher, and for both fabrics the coating process with $\mathrm{TiO}_{2}$ sol should be more effective (Lam et al. 2011; Calvimontes et al. 2011; Caschera et al. 2014; Navaneetha Pandiyaraj and Selvarajan 2008). This is confirmed by the results of a wettability study with $\mathrm{TiO}_{2}$ sol (Fig. 7).

Generally, both fabrics are very well wettable by $\mathrm{TiO}_{2}$ sol, but there are some differences in the wettability process. For cotton, the drop of sol spreads on both samples wherein it penetrates immediately to the structure of the plasma-pretreated fabric. In the case of viscose, a flat drop of sol is formed, and the contact angles before and after plasma treatment are $23^{\circ}$ and $18^{\circ}$, respectively (Fig. 7). Under the same conditions of the sol application, the content of $\mathrm{TiO}_{2}$ is higher for cotton, which is confirmed by the results of the SEM/EDS (Figs. 14, 15).

The impact of MW treatment is presented on the basis of SEM images of cotton fabric (Fig. 8). No changes or damage of the cotton fiber surface morphology was observed. The same results were observed for the viscose fabric (not shown). The effect of microwave treatment on the fibers was evaluated by Raman analysis (Fig. 9). In the case of cotton (Fig. 9a), the characteristic bands are stretching COC at $1098 \mathrm{~cm}^{-1}$, a group of four bands $(353,411,457$ and $580 \mathrm{~cm}^{-1}$ ), bending COC and CCC, methylene bands (900, 1270, 1378, $1468 \mathrm{~cm}^{-1}$ ) and C-H stretching at $2898 \mathrm{~cm}^{-1}$. No changes after MW treatment were observed between raw cotton (spectrum I) and MWtreated cotton (spectrum II). Characteristic viscose bands included stretching COC at $1100 \mathrm{~cm}^{-1}$, bending COC and CCC at $(332,381,438,454)$, methylene bands $\left(920,1297,1341,1384,1482 \mathrm{~cm}^{-1}\right)$ and $\mathrm{C}-\mathrm{H}$ 

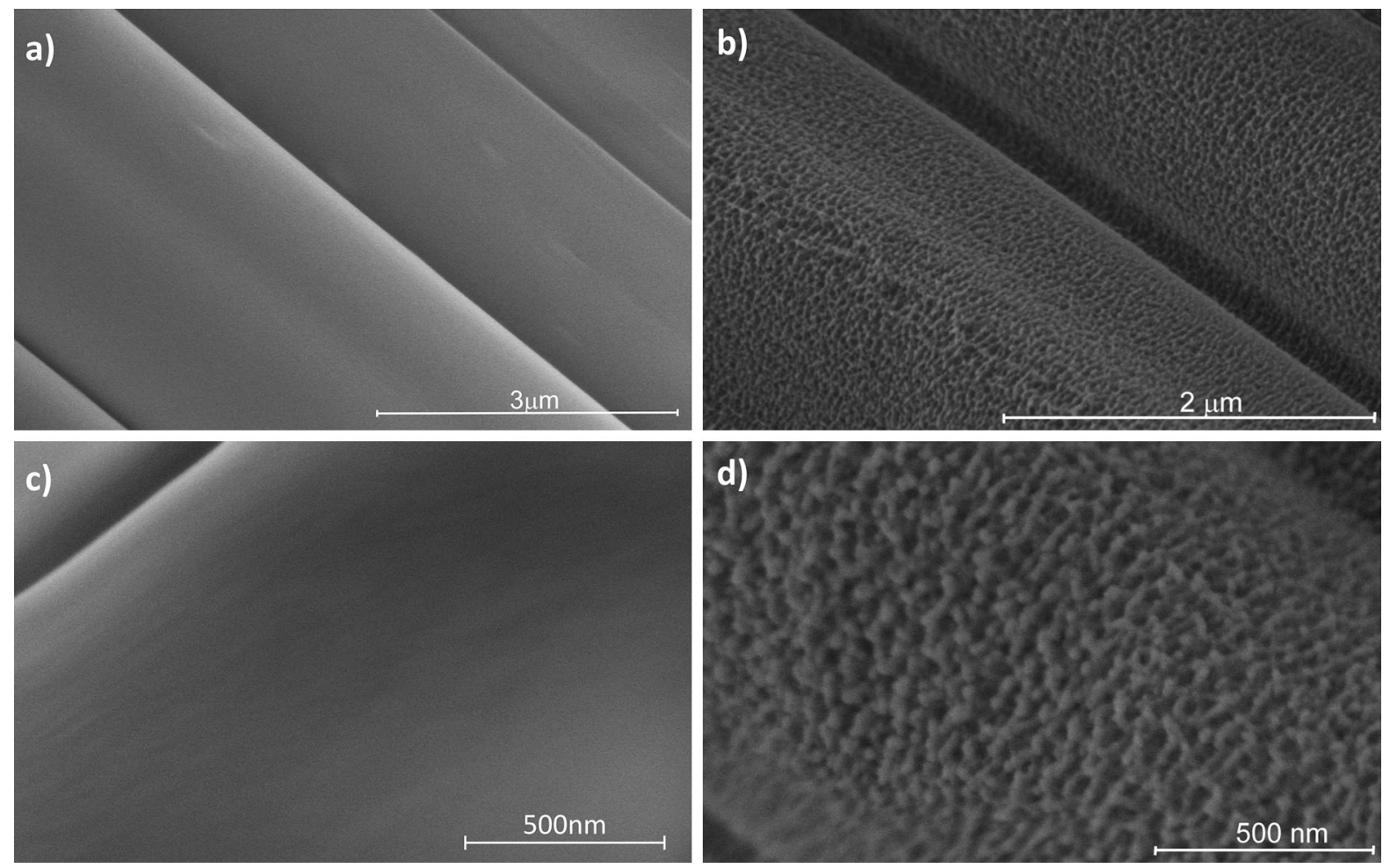

Fig. 4 SEM images of raw viscose $(\mathbf{a}, \mathbf{c} \times 30,000$ and $\times 120,000$ magnifications $)$ and 30 -min plasma-treated viscose $(\mathbf{b}, \mathbf{d} \times 30,000$ and $\times 120,000$ magnifications)

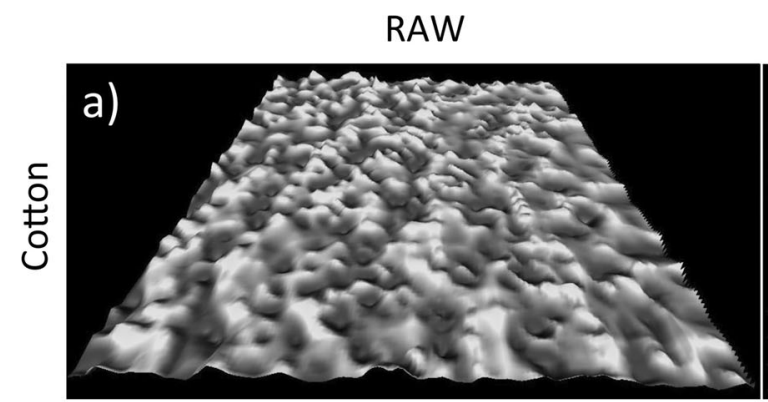

RMS $44 \mathrm{~nm}$

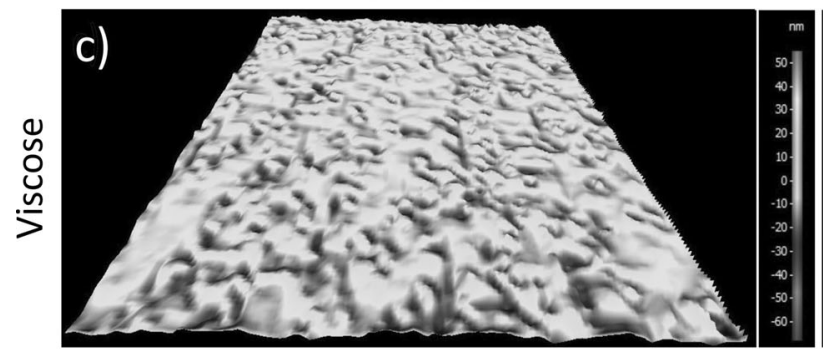

RMS $9 \mathrm{~nm}$

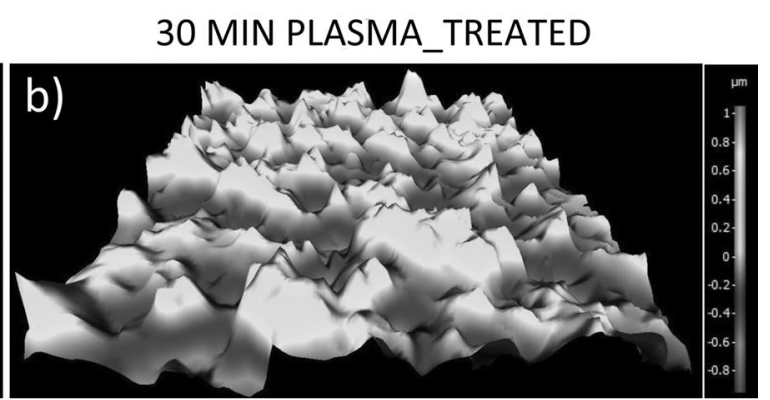

RMS 166 nm

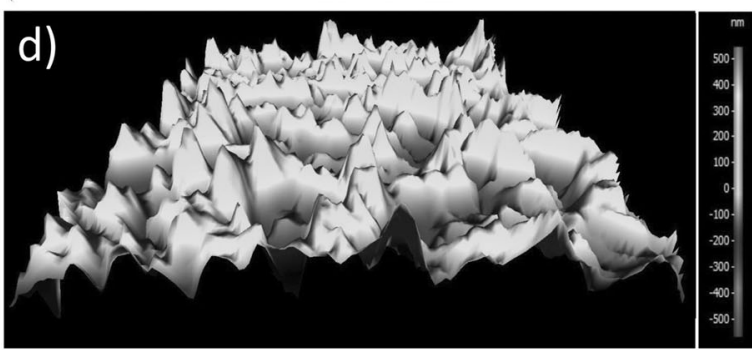

RMS $112 \mathrm{~nm}$

Fig. 5 The 3D SEM pictures of a raw cotton, b 30-min plasma-treated cotton, $\mathbf{c}$ raw viscose and $\mathbf{d}$ 30-min plasma-treated viscose with the root-mean-square-height value in the selected area 
Fig. 6 FTIR analysis of a raw cotton, b 30-min plasma-treated cotton, $\mathbf{c}$ raw viscose and $\mathbf{d}$ 30-min plasma-treated viscose

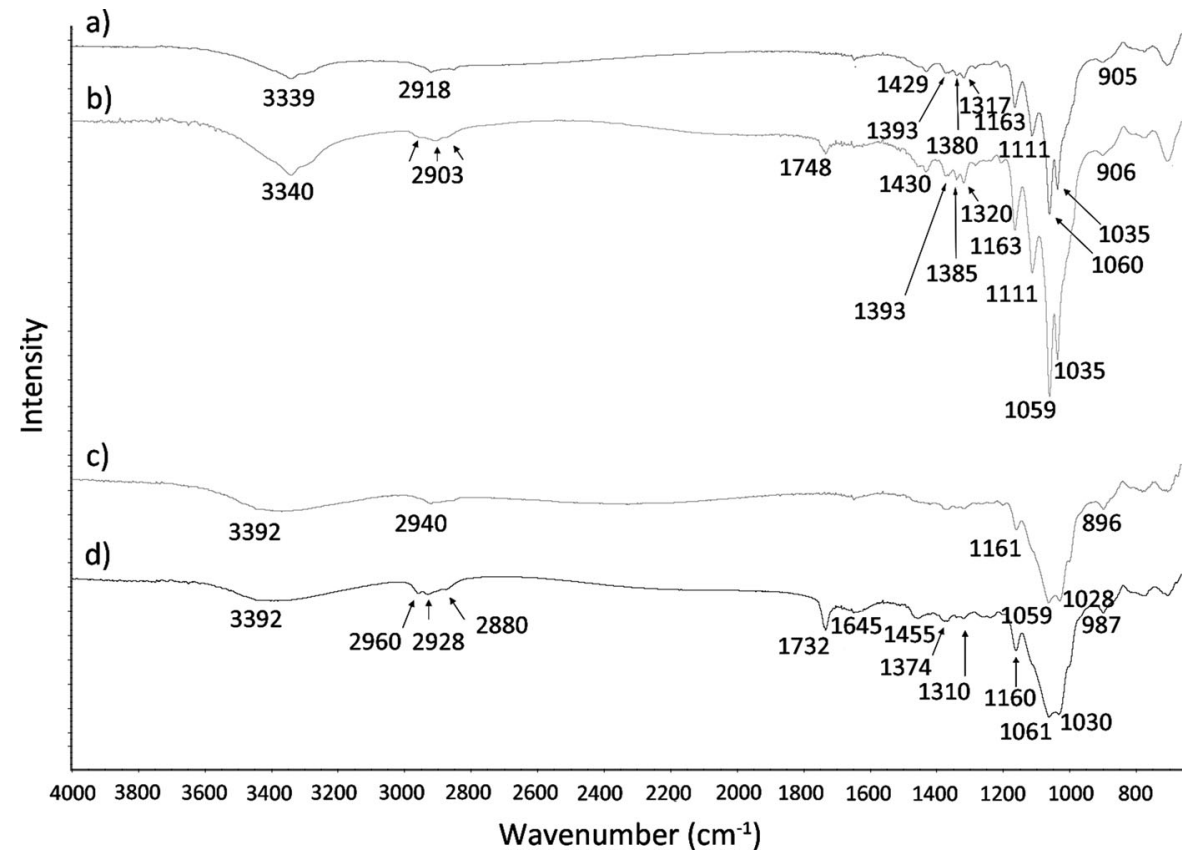

Table 2 Contact angle, surface free energy and work of adhesion of cotton and viscose fabrics

Fig. 7 The wettability of a raw cotton, b 30-min plasma-treated cotton, $\mathbf{c}$ raw viscose cotton and d 30-min plasma-treated viscose

\begin{tabular}{|c|c|c|c|c|}
\hline \multirow[t]{2}{*}{ Standard liquid } & \multicolumn{2}{|c|}{ Cotton fabric } & \multicolumn{2}{|c|}{ Viscose fabric } \\
\hline & Raw & Plasma-treated & Raw & Plasma-treated \\
\hline \multicolumn{5}{|l|}{ Contact angle $\left({ }^{\circ}\right)$} \\
\hline Water & $55 \pm 5$ & $10 \pm 2$ & $50 \pm 3$ & $7 \pm 2$ \\
\hline Diiodomethane & $40 \pm 3$ & $4 \pm 2$ & $56 \pm 5$ & $18 \pm 4$ \\
\hline Formamide & $60 \pm 7$ & $8 \pm 3$ & $52 \pm 4$ & $16 \pm 2$ \\
\hline \multicolumn{5}{|c|}{ Surface free energy $(\mathrm{SFE})\left(\mathrm{mJ} / \mathrm{m}^{2}\right)$} \\
\hline SFE & $47 \pm 3$ & $73 \pm 2$ & $49 \pm 4$ & $72 \pm 2$ \\
\hline$\gamma^{\mathrm{d}}$ & 31 & 41 & 26 & 40 \\
\hline$\gamma^{\mathrm{p}}$ & 16 & 32 & 23 & 32 \\
\hline \multicolumn{5}{|c|}{ Work of adhesion (Wa) $\left(\mathrm{mJ} / \mathrm{m}^{2}\right)$} \\
\hline Wa & 115 & 145 & 120 & 145 \\
\hline
\end{tabular}

(a)

$R \quad$ (b)

$\mathrm{R}$

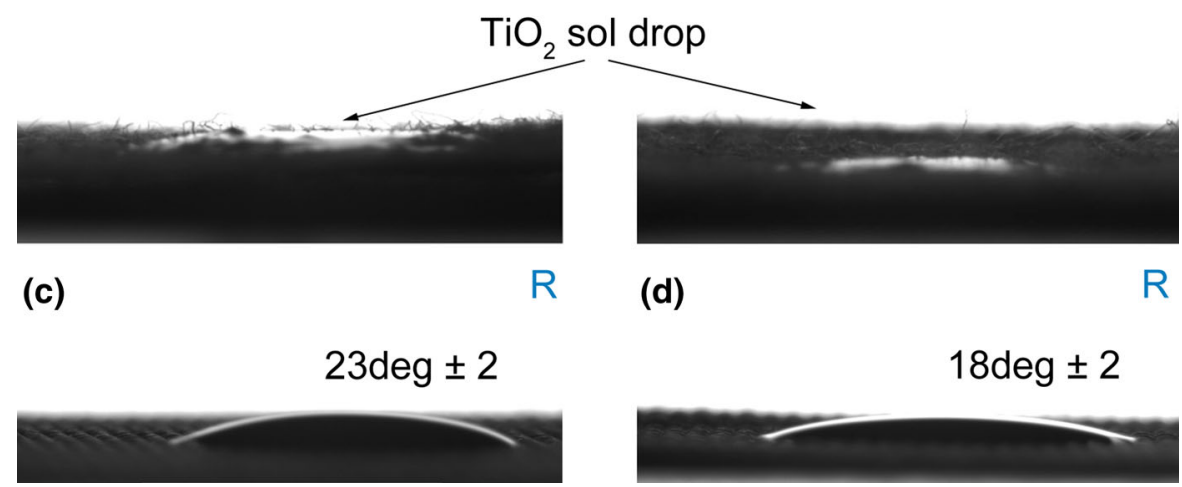



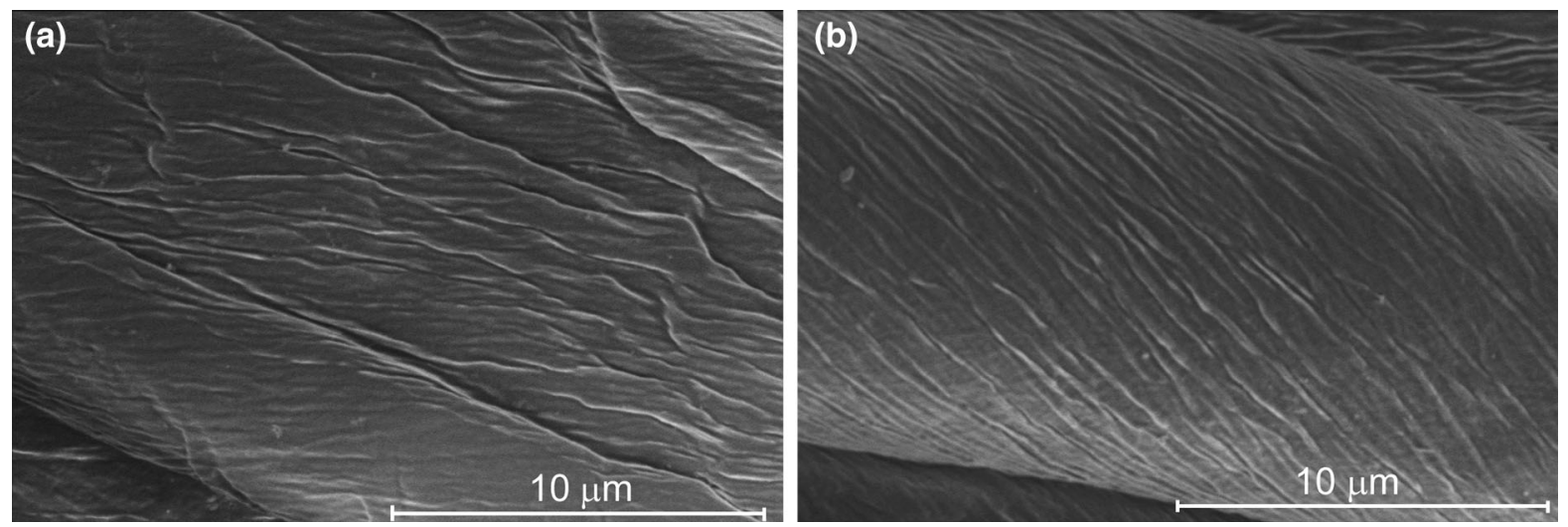

Fig. 8 SEM images of a raw cotton fabric and $\mathbf{b}$ cotton fabric after MW treatment at $650 \mathrm{~W}, 15$ min with $\times 10,000$ magnification

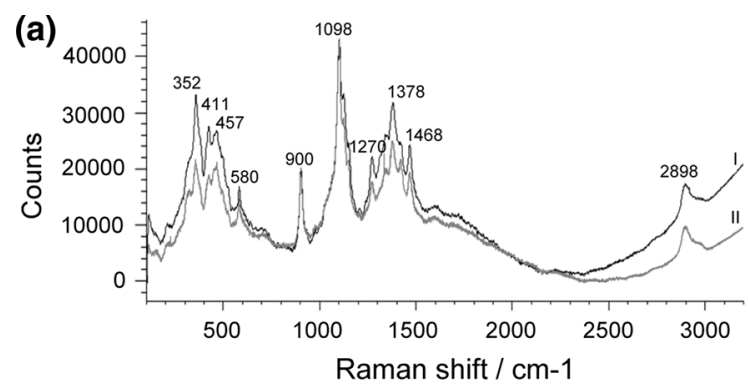

(b)

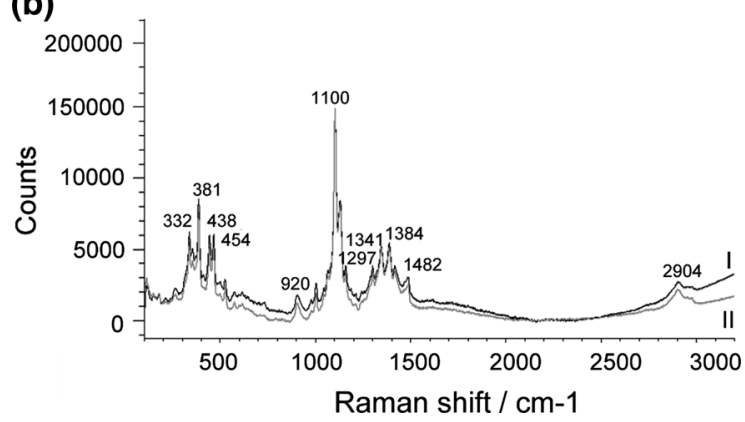

Fig. 9 Raman spectra of a cotton and $\mathbf{b}$ viscose fabrics: raw (I) and after MW treatment, $650 \mathrm{~W}, 15 \mathrm{~min}(I I)$

stretching at $2904 \mathrm{~cm}^{-1}$ (Fig. 9b); this also did not reveal changes between raw viscose (spectrum I) and MW-treated viscose (spectrum II) (Kavkler and Demšar 2011).

Raman spectra and map pictures obtained for cotton (Fig. 10a) and viscose (Fig. 10b) fabric modified with $\mathrm{TiO}_{2}$ sol and MW treated at $650 \mathrm{~W}$ for $15 \mathrm{~min}$ are presented. The detected spectra prove that on both fabrics $\mathrm{TiO}_{2}$ is present in the anatase form (band at
$150 \mathrm{~cm}^{-1}$ for cotton and $153 \mathrm{~cm}^{-1}$ for viscose) (Fig. 10a, b, respectively). These strong sharp peaks are analogous to the $142-\mathrm{cm}^{-1}$ anatase O-Ti-O bending vibration (Ohsaka et al. 1978). As a result of the physical interaction between the titania and fabric, the main anatase band is shifted to larger wavelengths. Other anatase bands at 194, 393, 515 and $637 \mathrm{~cm}^{-1}$ (Ohsaka et al. 1978) were not observed because there are strong bands of cotton and viscose fibers in this range. Raman map pictures show the distribution of $\mathrm{TiO}_{2}$-anatase on the fiber surface. The dots on the pictures indicate where the Raman spectra were collected and the main anatase characteristic band was found.

The XRD results for $\mathrm{TiO}_{2}$ coatings on both fabrics confirmed the formation of crystalline $\mathrm{TiO}_{2}$. Figure 11 presents the XRD spectra of cotton (Fig. 11a) and viscose (Fig. 11b) modified with $\mathrm{TiO}_{2}$. The characteristic peaks centered at two theta around 29.50; three peaks that appeared as one wide one $(43.22 ; 44.24$; $45.11)$ and 56.00 are visible, being characteristic for the $\mathrm{TiO}_{2}$-anatase phase (ref. pattern no. 00-064-0863). The intensity of the registered peaks is rather low; moreover, they are more pronounced in the case of $\mathrm{TiO}_{2}$-modified cotton fabric. This is also consistent with the results of Raman spectroscopy.

After reducing the power and time of $\mathrm{MW}$ treatment to $500 \mathrm{~W}$ and $10 \mathrm{~min}$, the $\mathrm{TiO}_{2}$ film on the fibers surface was a mixture of the anatase and amorphous form (Fig. 12). Besides the characteristic anatase bands, two bands at 440 and $620 \mathrm{~cm}^{-1}$ assigned to the amorphous form of titania were found (Zhang et al. 1998), clearly visible for viscose 
Fig. 10 Raman spectra and Raman maps of a cotton and b viscose fabrics with $\mathrm{TiO}_{2}$ after MW treatment at $650 \mathrm{~W}, 15 \mathrm{~min}$ (white dots on the map- $-\mathrm{TiO}_{2}$ anatase)
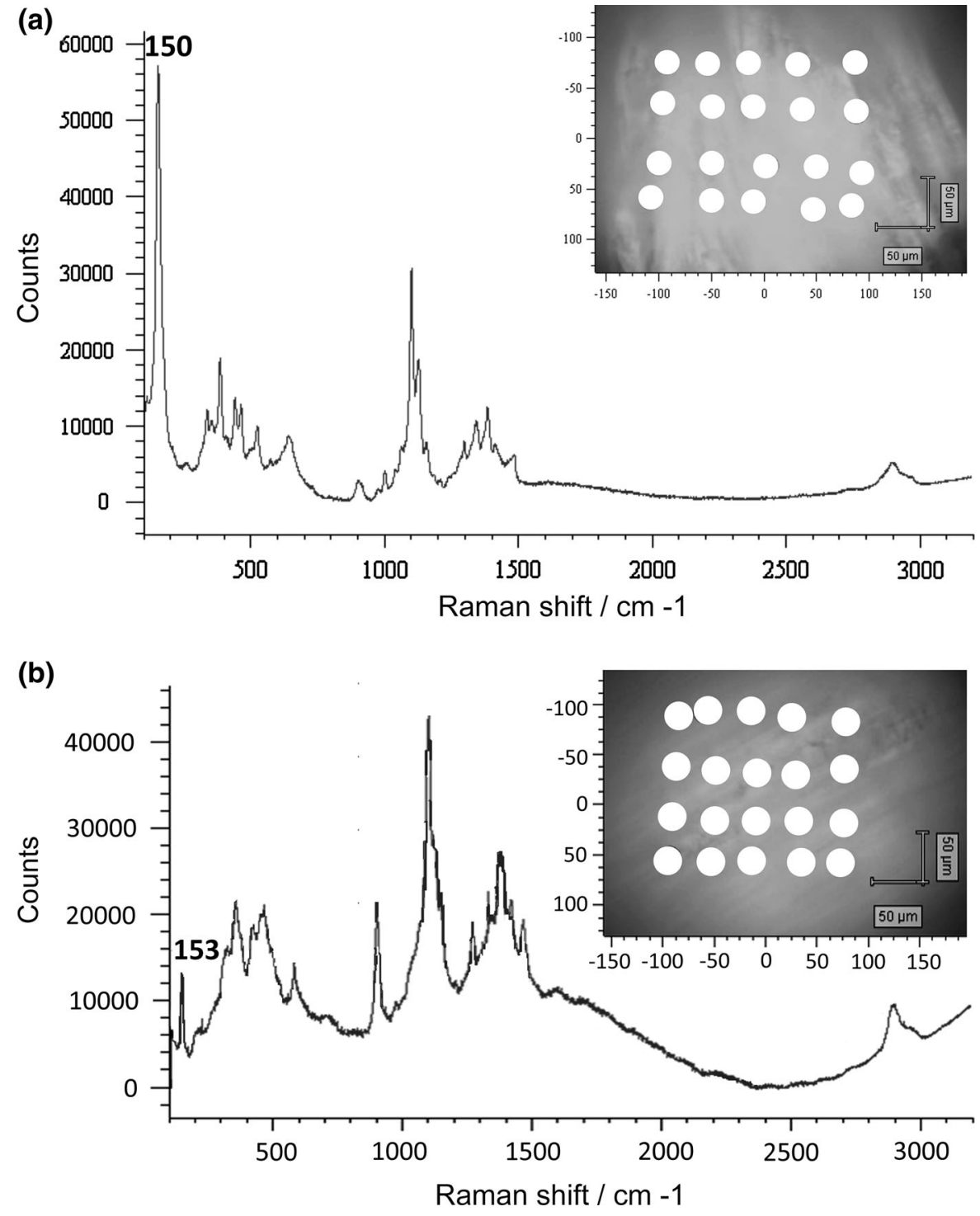

(Fig. 12b). In the case of cotton (Fig. 12a), the band at $440 \mathrm{~cm}^{-1}$ is an overlap with the cotton bands present in this region. Results of Raman analysis show that for the transformation of $\mathrm{TiO}_{2}$ to the anatase form, suitable MW treatment conditions must be selected.

SEM images of $\mathrm{TiO}_{2}$ coatings in the anatase form on the Si wafers and fibers are presented in Figs. 13, 14 and 15.

$\mathrm{TiO}_{2}$ film on the Si wafer (Fig. 13) creates a film with varied surface topography compared to smooth $\mathrm{TiO}_{2}$ film-anatase on the $\mathrm{Si}$ wafer obtained by calcination for $2 \mathrm{~h}$ at $500{ }^{\circ} \mathrm{C}$ (Cieslak et al. 2015). $\mathrm{TiO}_{2}$ forms a continuous coating on the cotton and viscose fibers without any gaps or agglomerates (Figs. 14, 15). SEM/EDS maps show that $\mathrm{Ti}$ is distributed on all fibers, white dots-Ti (Figs. 14c, 15c). The thickness of $\mathrm{TiO}_{2}$ film is $180 \pm 7$ and $140 \pm 8 \mathrm{~nm}$ for cotton and viscose, respectively. The content of $\mathrm{Ti}$ evaluated on the basis of SEM/EDS analysis is nearly four times higher for cotton. It can be concluded that compared to the roughness of the fiber surface of viscose, the thickness of the $\mathrm{TiO}_{2}$ layer and Ti content are higher for cotton fabrics.

The different behaviors of both of the studied cellulose fabrics toward plasma pretreatment and the effect of $\mathrm{TiO}_{2}$ sol application are related to differences 

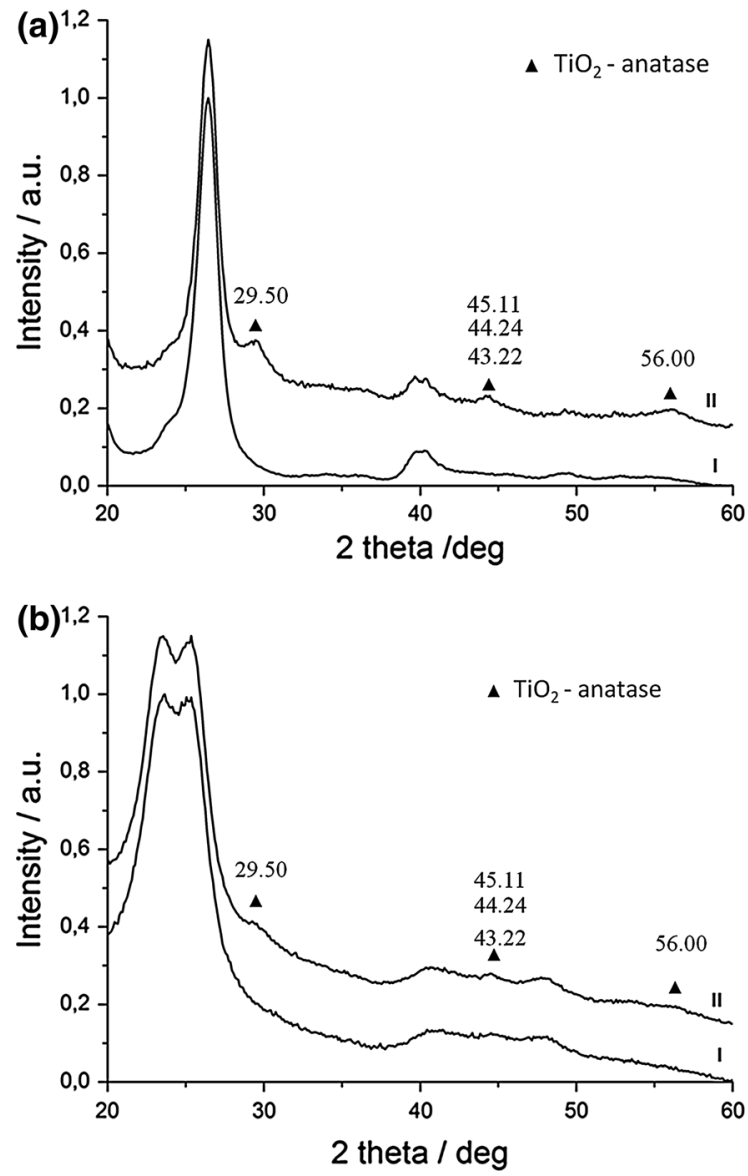

Fig. 11 XRD spectra of a cotton and $\mathbf{b}$ viscose I raw and II with $\mathrm{TiO}_{2}$ after MW treatment at $650 \mathrm{~W}, 15 \mathrm{~min}$

in their morphology and topography. Surface ablation during plasma treatment is different for the cotton fiber and viscose fibers. The cotton fiber with a bean-shaped cross section has a concentric layered structure with an outer separable cuticle layer composed of wax and pectin materials, which are removed during the pretreatment processes (scouring and bleaching). The next, primary wall is composed of cellulosic crystalline fibrils, and the secondary three-layer wall consists of closely packed parallel cellulose fibrils. The degree of polymerization of cotton is $9000-15,000$, and the crystallinity of cellulose is approximately $70 \%$. In the viscose fiber with a skincore structure, the skin contains numerous small crystallites with a larger total surface area than the core composed of fewer but larger crystallites. Viscose is characterized by the more than 30 times lower degree of polymerization, and its crystallinity degree
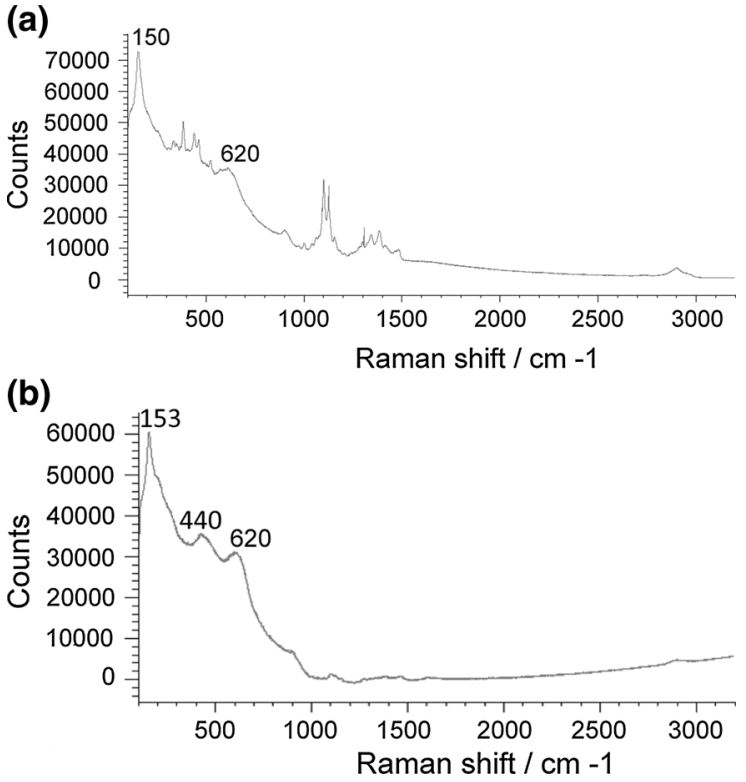

Fig. 12 Raman spectra of $\mathbf{a}$ cotton and $\mathbf{b}$ viscose fabrics with $\mathrm{TiO}_{2}$ film after MW treatment at $500 \mathrm{~W}, 10 \mathrm{~min}$

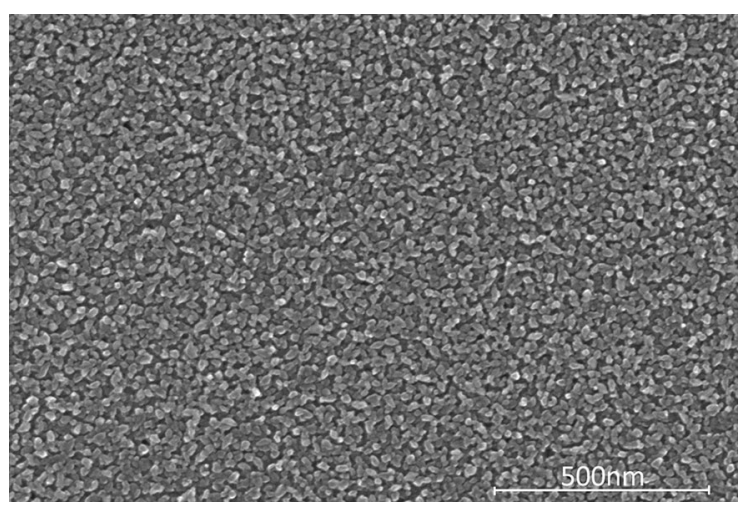

Fig. 13 SEM images of $\mathrm{TiO}_{2}$ film on $\mathrm{Si}$ wafers (smooth substrate) after MW treatment at $650 \mathrm{~W}, 15 \mathrm{~min}(\times 120,000$ magnification)

is lower by almost $40 \%$ in comparison to cotton (Duckett 1975).

The unmodified and modified cotton fabric showed higher susceptibility to nicotine sorption compared to viscose fabric. On the basis of exponential equations, the constant rate of nicotine decomposition was determined $(k)$. The ratio of constant $\mathrm{k}$ for modified and unmodified cotton and viscose fabrics is 3.3 and 2.0, respectively. After application of the total irradiation dose of $405.8 \mathrm{~kJ} / \mathrm{m}^{2}$, the nicotine concentration decreased for unmodified and modified cotton and 


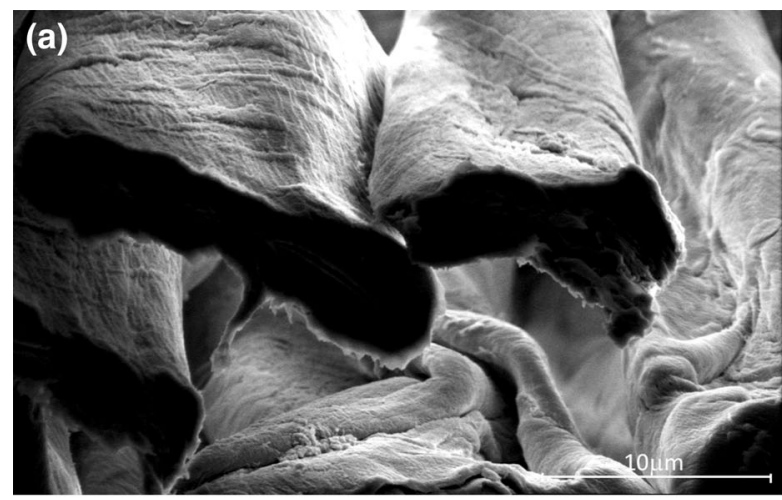

(c)
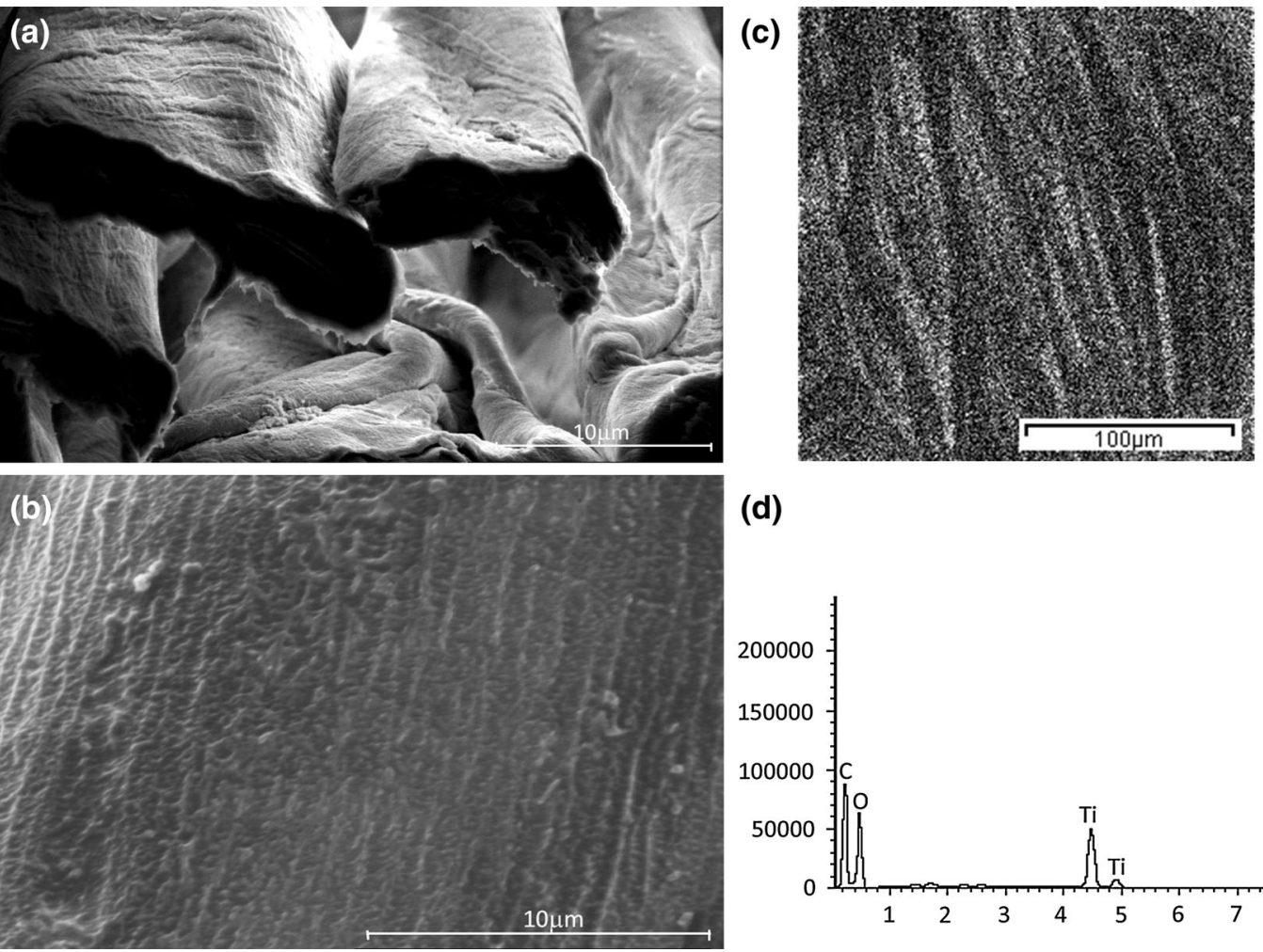

(d)

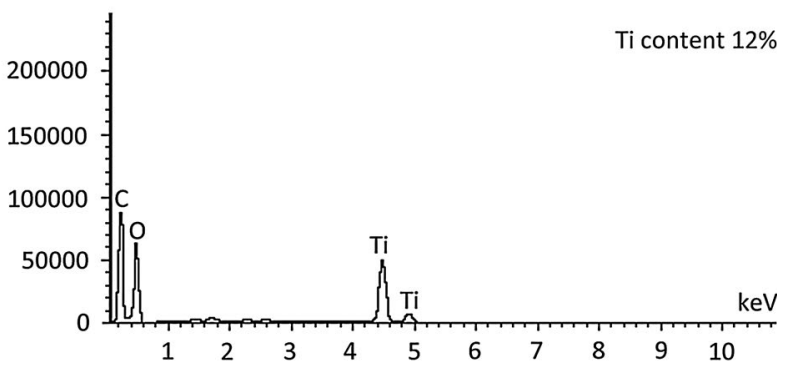

Fig. 14 SEM images of $\mathbf{a}, \mathbf{b} \mathrm{TiO}_{2}$ coatings on cotton after MW treatment at $650 \mathrm{~W}, 15$ min with $\times 6500$ and $\times 30,000$ magnifications, c SEM/EDS map of Ti distribution and $\mathbf{d}$ EDS spectrum of cotton textile modified with $\mathrm{TiO}_{2}$ after MW treatment at $650 \mathrm{~W}$, 15 min

viscose fabrics by about 21, 56, 45 and $64 \%$, respectively. A faster decrease in the nicotine concentration of modified fabrics results from their photocatalytic properties (Fig. 16).

The $\mathrm{Ti}$ contents before and after washing were evaluated on the basis of SEM/EDS analysis (Fig. 17). After washing, the $\mathrm{Ti}$ content on cotton fabric decreased from 12 to $11 \%$ and on viscose fabric from about 3 to $2.6 \%$. Windler et al. (2012) investigated the release of titanium dioxide from consumer products (T-shirts and pants) of different compositions, also including cotton. The results indicated that functional textiles release some $\mathrm{TiO}_{2}$ particles, but the amount is relatively low and mostly not in the nanoparticulate range, and $\mathrm{Ti}$ can occur.

The average values of the breaking force and breaking elongation of both fabrics before and after applied modifications are listed in Table 3.

Slight changes of the tensile strength of cotton after each modification (plasma treatment, microwave treatment and plasma/ $/ \mathrm{TiO}_{2} /$ microwave treatment) were observed. It can be concluded that cotton fabric retains its physical properties after modifications. Contrary to cotton fabric, the tensile strength of viscose fabric decreased after plasma treatment (about $14 \%$ ), microwave treatment (about $19 \%$ ) and the most for $\mathrm{TiO}_{2}$-modified fabric; the breaking force dropped from 499 to $275 \mathrm{~N}$ (about $45 \%$ ). Breaking elongation for cotton and viscose increased after the applied modifications. The developed method of modification with $\mathrm{TiO}_{2}$ and microwave treatment tested on two cellulose fabrics is more suitable for cotton fabric because of the significant reduction of the tensile strength of viscose fabric.

The influence of UV irradiation on raw and $\mathrm{TiO}_{2}-$ anatase-modified fabrics was evaluated (Fig. 18). The results show that raw and $\mathrm{TiO}_{2}$-modified cotton fabrics are stable under UV irradiation. In case of raw and $\mathrm{TiO}_{2}$-modified viscose fabrics, $\mathrm{UV}$ irradiation affects their tensile strength. The tensile strength of raw viscose after UV irradiation of $5184 \mathrm{~kJ} / \mathrm{m}^{2}$ decreased by nearly $7 \%$, and there were minor changes. For 


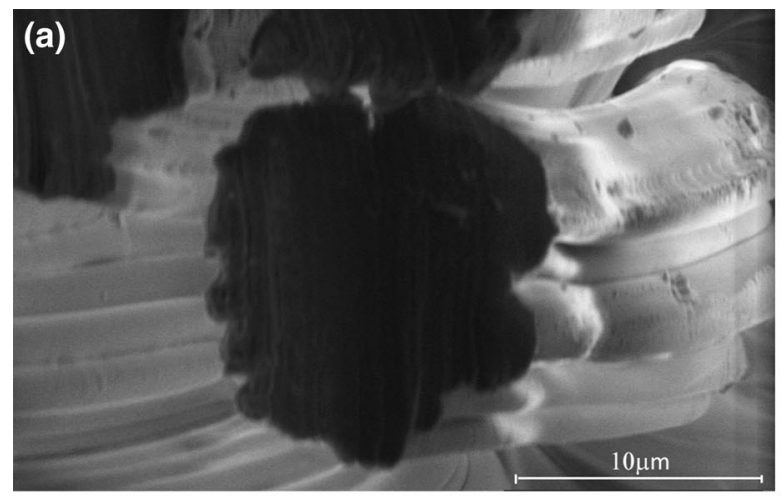

(c)
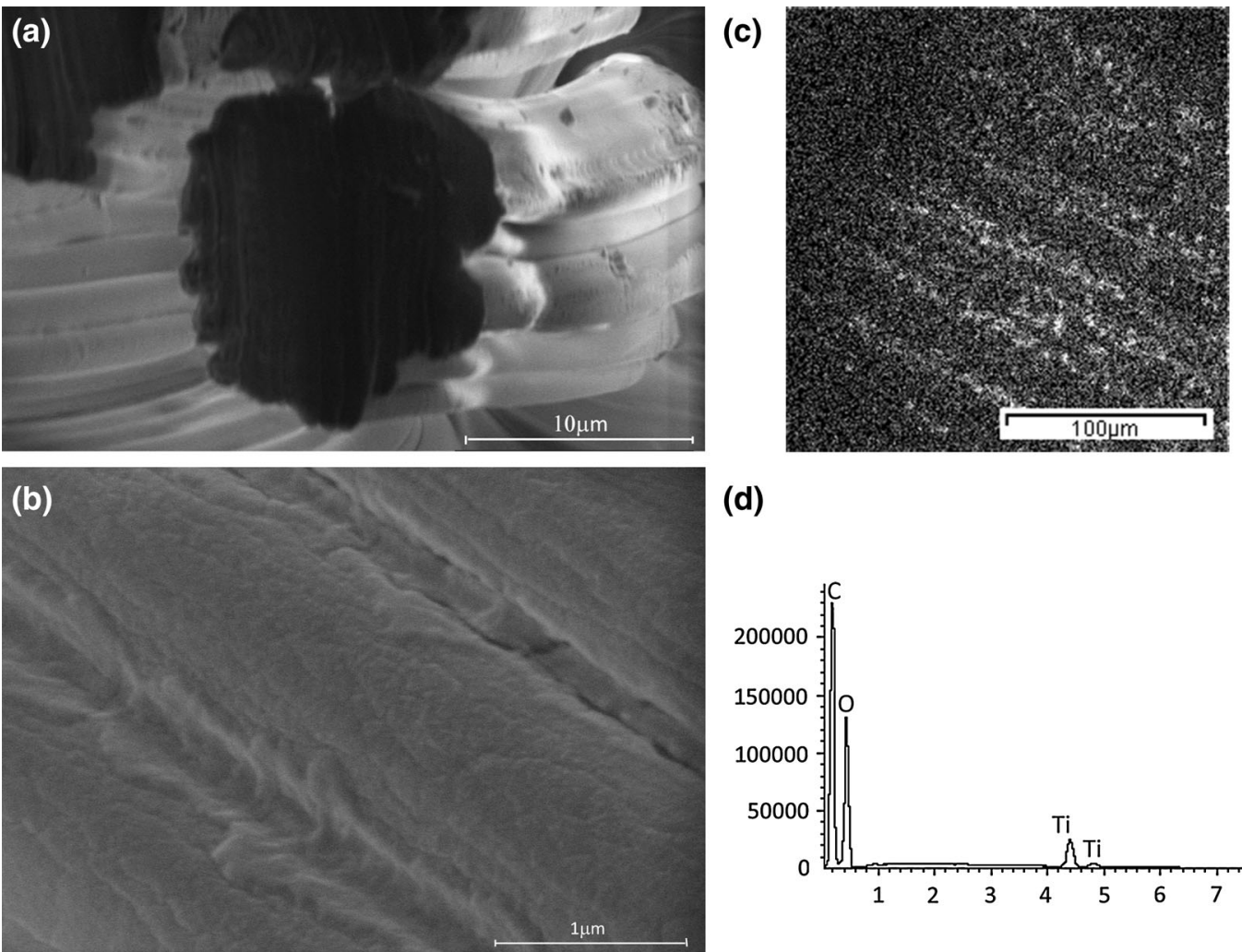

(d)

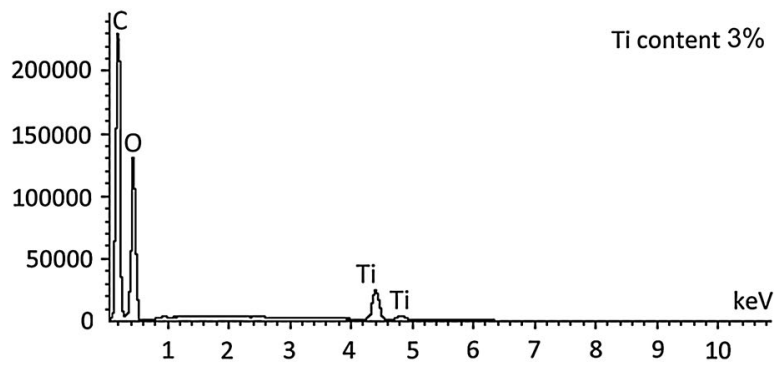

Fig. 15 SEM images of $\mathrm{TiO}_{2}$ coatings $\mathbf{a}, \mathbf{b}$ on viscose after $\mathrm{MW}$ treatment at $650 \mathrm{~W}, 15 \mathrm{~min}$, with $\times 6500$ and $\times 50,000$ magnifications, c SEM/EDS map of Ti distribution and d EDS spectrum of viscose modified with $\mathrm{TiO}_{2}$ after MW treatment at $650 \mathrm{~W}, 15 \mathrm{~min}$

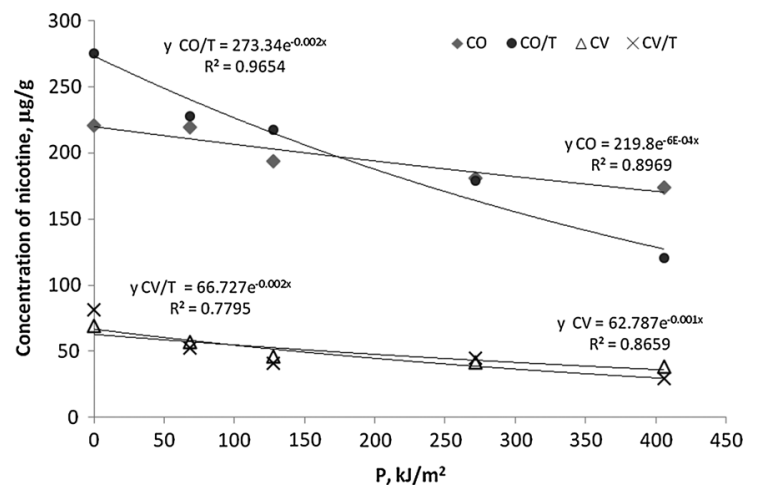

Fig. 16 The influence of the sunlight irradiation dose $(P)$ on the nicotine concentration for unmodified and $\mathrm{TiO}_{2}$ modified cotton and viscose fabrics. $C O$ cotton, $C O / T$ cotton modified with $\mathrm{TiO}_{2}, C V$ viscose, $C V / T$ viscose modified with $\mathrm{TiO}_{2}$

$\mathrm{TiO}_{2}$-modified viscose fabric, the tensile strength decreased by about $16 \%$ (from 275 to $232 \mathrm{~N}$ ) (Fig. 18a). Breaking elongation for cotton and viscose fabrics increased after UV irradiation (Fig. 18b).

\section{Conclusions}

Application of microwave treatment to the formation a $\mathrm{TiO}_{2}$-anatase layer directly on cotton and viscose fabrics was reported. In this study, two selected conditions-650 W, $15 \mathrm{~min}$ and $500 \mathrm{~W}, 10 \mathrm{~min}-$ were investigated. The microwave conditions influenced the $\mathrm{TiO}_{2}$ form; it obtained an anatase form $\left(650 \mathrm{~W}, 15 \mathrm{~min}, 181^{\circ} \mathrm{C}\right)$ and a mixture of the anatase and amorphous form $\left(500 \mathrm{~W} 10 \mathrm{~min}, 110^{\circ} \mathrm{C}\right)$. The conversion of $\mathrm{TiO}_{2}$ to the anatase form takes place at temperatures below $200{ }^{\circ} \mathrm{C}$, which opens up many possibilities for modifications of different fibers with low thermal stability. The microwave step replaces the calcination process at around $500{ }^{\circ} \mathrm{C}$ and can only be used for fibers with high thermal resistance. To improve the surface properties of fibers and the $\mathrm{TiO}_{2}$ sol application, low-temperature air plasma pretreatment was used. This resulted in better wettability of both fabrics by $\mathrm{TiO}_{2}$ sol and significant growth in nano-roughness. The value of the root mean square 

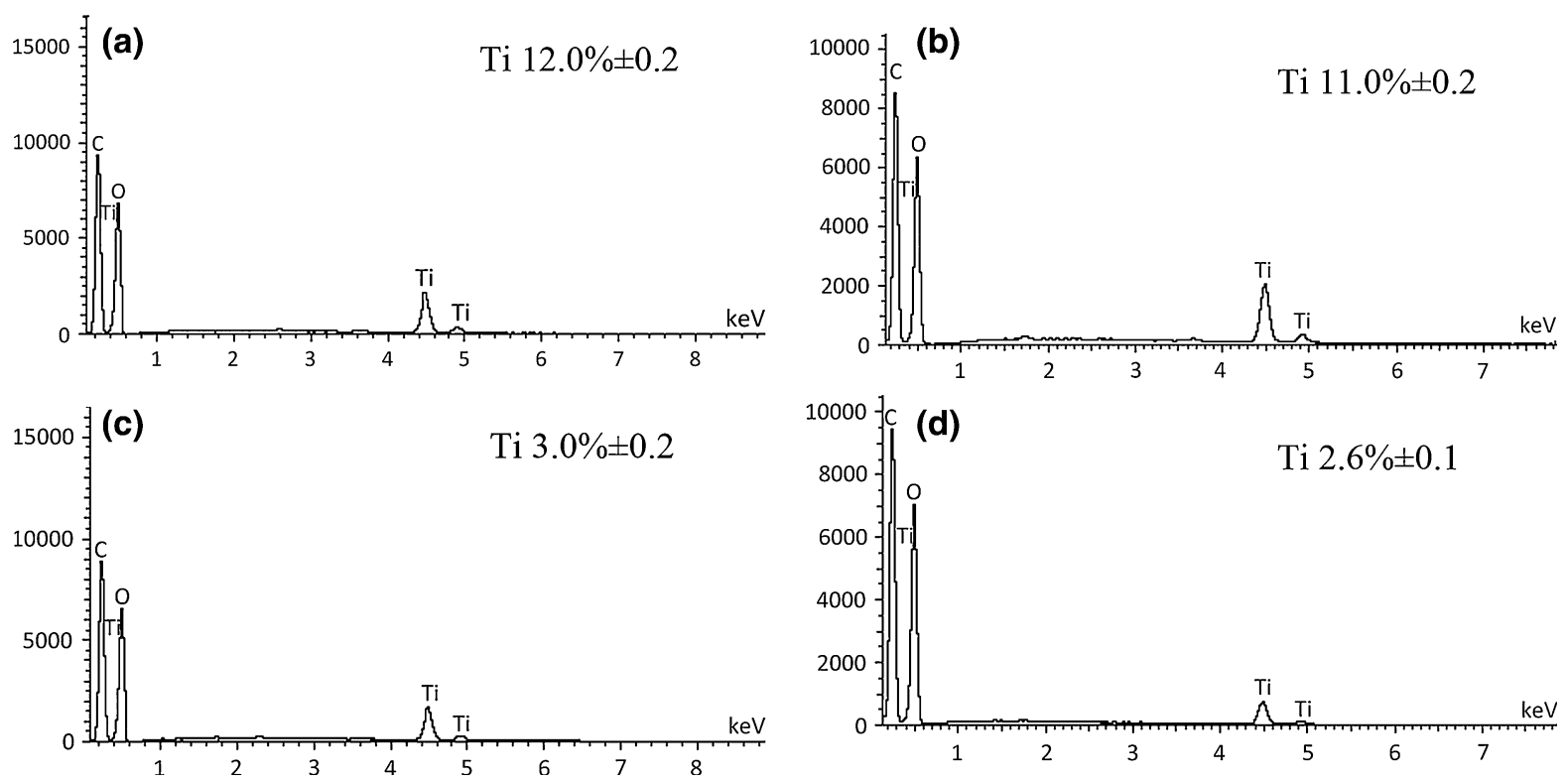

Fig. 17 Results of EDS analysis for a cotton fabric before washing, $\mathbf{b}$ cotton fabric after washing, $\mathbf{c}$ viscose fabric before washing and d viscose fabric after washing

Table 3 Results of the tensile strength of cotton and viscose fabrics before and after each step of modification

\begin{tabular}{llllll}
\hline Fabric sample & \multicolumn{2}{l}{ Cotton } & & \multicolumn{2}{l}{ Viscose } \\
\cline { 2 - 3 } & Breaking force $(N)$ & Breaking elongation $(\%)$ & & Breaking force $(N)$ & Breaking elongation $(\%)$ \\
\hline Raw & $422 \pm 5$ & $10.1 \pm 0.1$ & $499 \pm 4$ & $16.7 \pm 0.5$ \\
Plasma treated & $405 \pm 7$ & $10.7 \pm 0.3$ & $431 \pm 6$ & $17.5 \pm 0.2$ \\
Microwave treated & $450 \pm 8$ & $13.5 \pm 0.8$ & & $404 \pm 4$ & $26.6 \pm 0.9$ \\
Plasma/TiO $/$ microwave treated & $428 \pm 5$ & $12.6 \pm 0.6$ & $275 \pm 8$ & $21.0 \pm 0.2$ \\
\hline
\end{tabular}

(RMS) increased from 44 to $166 \mathrm{~nm}$ (cotton) and from 9 to $112 \mathrm{~nm}$ (viscose). The surface free energy increased by about 26 and $23 \mathrm{~mJ} / \mathrm{m}^{2}$ for cotton and viscose, respectively. In the FTIR spectrum, there were new bands at 1748 and $1732 \mathrm{~cm}^{-1}$ corresponding to $\mathrm{C}=\mathrm{O}$ stretching, which causes the increase in the hydrophilicity and adhesion properties. The final effect of modification differs for viscose and cotton fabrics. Generally, the wettability of cotton by $\mathrm{TiO}_{2}$ sol is better, the nano-roughness and $\mathrm{TiO}_{2}$ layer thickness are higher, and the amount of $\mathrm{Ti}$ is four times higher compared to viscose fabrics. $\mathrm{TiO}_{2}$-modified cotton and viscose fabrics accelerate the decomposition of the adsorbed nicotine and thus its accumulation in fibers. The ratio of constant $\mathrm{k}$ for modified and unmodified cotton and viscose fabrics is 3.3 and 2.0, respectively. The nicotine concentration decreased for unmodified and modified cotton and viscose fabrics by about 21, 56, 45 and $64 \%$, respectively, after a UV irradiation dose of $405.8 \mathrm{~kJ} / \mathrm{m}^{2}$. No significant strength reduction after modifications and UV irradiation of cotton fabric was observed. For viscose, a UV dose irradiation of $5184 \mathrm{~kJ} / \mathrm{m}^{2}$ decreased the tensile strength by about 7 and $16 \%$ for raw and $\mathrm{TiO}_{2^{-}}$ modified viscose, respectively. The tensile strength of the viscose fabric after $\mathrm{TiO}_{2}$ anatase modification reduced by about $45 \%$. The Ti contents after washing decreased from 12 to $11 \%$ (cotton) and from 3 to $2.6 \%$ (viscose). The durability of the $\mathrm{TiO}_{2}$ film on the fabric surface was satisfactory. The developed method 
Fig. 18 Results of a breaking force and b breaking elongation for cotton and viscose fabrics before and after UV irradiation. $\mathrm{CO}$ cotton, $\mathrm{CO} /$ $T$ cotton modified with $\mathrm{TiO}_{2}$, $C V$ viscose, $C V / T$ viscose modified with $\mathrm{TiO}_{2}$
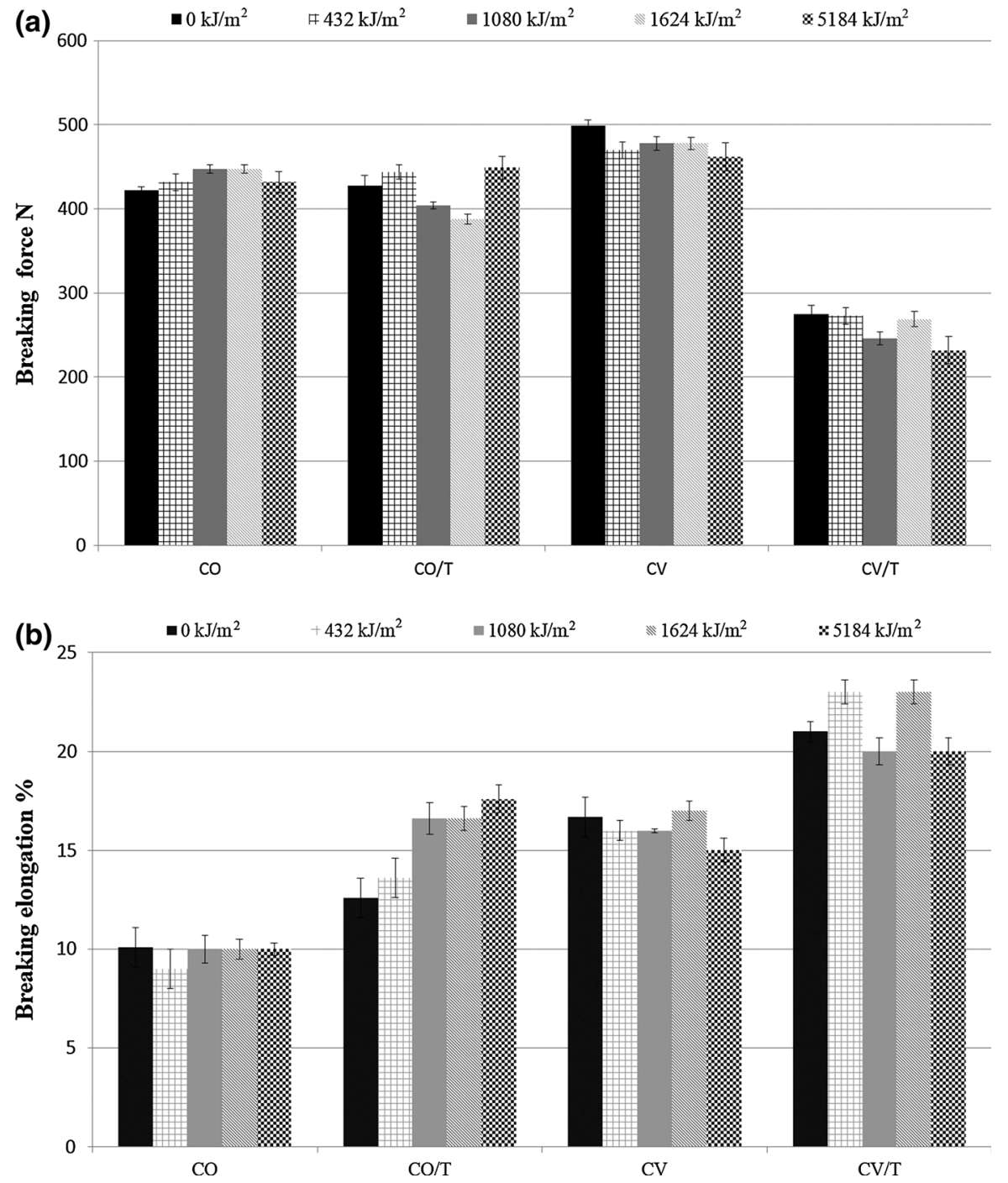

of modifying cotton and viscose with $\mathrm{TiO}_{2}$ to obtain the anatase form directly on the cellulose fabric surface is more effective for cotton fabric because of the reduction of the tensile strength of viscose fabric.

Acknowledgments This study was carried out within the Key Project-POIG.01.03.01-00-004/08 Functional nano- and micro textile materials-NANOMITEX co-financed by the European Union with the financial resources of the European Regional Development Fund and the National Centre for Research and Development within the framework of the Innovative Economy Operational Programme, 2007-2013, Priority 1 ; research and development of modern technologies, activity 1.3; supporting R\&D projects for enterprises undertaken by science establishments, subactivity 1.3.1. Development projects.
Open Access This article is distributed under the terms of the Creative Commons Attribution 4.0 International License (http:// creativecommons.org/licenses/by/4.0/), which permits unrestricted use, distribution, and reproduction in any medium, provided you give appropriate credit to the original author(s) and the source, provide a link to the Creative Commons license, and indicate if changes were made.

\section{References}

Abidi N, Cabrales L, Hequet E (2009) Functionalization of a cotton fabric surface with titania nanosols: applications for self-cleaning and UV-protection properties. ACS Appl Mater Interfaces 1:2141-2146 
Behzadnia A, Montazer M, Rashidi A, Mahmoudi Rad M (2014a) Rapid Sonosynthesis of N-Doped Nano $\mathrm{TiO}_{2}$ on wool fabric at low temperature: introducing self-cleaning, hydrophilicity, antibacterial/antifungal properties with low alkali solubility, yellowness and cytotoxicity. Photochem Photobiol 90:1224-1233

Behzadnia A, Montazer M, Rashidi A, Rad MM (2014b) Sonosynthesis of nano $\mathrm{TiO}_{2}$ on wool using titanium isopropoxide or butoxide in acidic media producing multifunctional fabric. Ultrason Sonochem 21:1815-1826

Calvimontes A, Mauersberger P, Nitschke M, Dutschk V, Simon F (2011) Effects of oxygen plasma on cellulose surface. Cellulose 18:803-809

Caschera D, Mezzi A, Cerri L, Caro T, Riccucci C, Ingo GM, Padeletti G, Biasiucci M, Gigli G, Cortese B (2014) Effects of plasma treatments for improving extreme wettability behavior of cotton fabrics. Cellulose 21:741-756

Cieslak M, Schmidt H, Swiercz R, Wasowicz W (2009) $\mathrm{TiO}_{2} /$ $\mathrm{Ag}$ modified carpet fibres for the reduction of nicotine exposure. Fibres Text East Eur 17:59-65

Cieslak M, Puchowicz D, Schmidt H (2012) Evaluation of the possibility of using surface free energy study to design protective fabrics. Text Res J 82:1177-1189

Cieslak M, Schmidt H, Swiercz R, Wasowicz W (2014) Fibers susceptibility to contamination by environmental tobacco smoke markers. Text Res J 84:840-853

Cieslak M, Celichowski G, Giesz P, Nejman A, Puchowicz D, Grobelny J (2015) Formation of nanostructured $\mathrm{TiO}_{2^{-}}$ anatase films on the basalt fiber suraface. Surf Coat Tech 276:686-695

Duckett KE (1975) Surface properties of cotton fibers, fiber science series. In: Schick MJ (ed) Surface characteristics of fibers and textiles, part I. Marcel Dekker, New York and Basel, pp 64-70

Dupre A (1869) Theorie Mecanique de La Chaleur. GauthierVillan, Paris

Ibrahim NA, Refaie R, Ahmed AF (2010) Novel approach for attaining cotton fabric with multi-functional properties. $\mathrm{J}$ Ind Text 40:65-83

Ibrahim NA, Eid BM, Youssef MA, El-Sayedb SA, Salah AM (2012) Functionalization of cellulose-containing fabrics by plasma and subsequent metal salt treatments. Carbohyd Polym 90:908-914

Kadziola K, Piwonski I, Kisielewska A, Szczukocki D, Krawczyk B, Lisowska K, Sielski J (2014) The photoactivity of titanium dioxide coatings with silver nanoparticles prepared by sol-gel and reactive magnetron sputtering methods-comparative studies. Appl Surf Sci 288:503-512

Karahan HA, Özdoan E (2008) Improvements of surface functionality of cotton fibers by atmospheric plasma treatment. Fib and Polym 9:21-26

Karimi L, Mirjalili M, Yazdanshenas ME, Nazari A (2010) Effect of Nano $\mathrm{TiO}_{2}$ on self-cleaning property of crosslinking cotton fabric with succinic acid under UV irradiation. Photochem Photobiol 86:1030-1037

Karimi L, Yazdanshenas ME, Khajavi R, Rashidi A, Mirjalili M (2014) Using graphene/ $\mathrm{TiO}_{2}$ nanocomposite as a new route for preparation of electroconductive, self-cleaning, antibacterial and antifungal cotton fabric without toxicity. Cellulose 21:3813-3827
Kavkler K, Demšar A (2011) Examination of cellulose textile fibres in historical objects by micro-Raman spectroscopy. Spectrochim Acta A Mol Biomol Spectrosc 78:740-746

Kiwi J, Pulgarin C (2010) Innovative self-cleaning and bactericide textiles. Catal Today 151:2-7

Lam YL, Kan CW, Yuen CW (2011) Physical and chemical analysis of plasma-treated cotton fabric subjected to wrinkle-resistant finishing. Cellulose 8:493-503

Li X, Wang L, Lu X (2010) Preparation of silver-modified $\mathrm{TiO}_{2}$ via microwave-assisted metod and its photocatalytic activity for toluene degradation. J Hazard Mater 177:639-647

Liu Y, Yang S, Hong J, Sun C (2007) Low-temperature preparation and microwave photocatalytic activity study of $\mathrm{TiO}_{2}$-mounted activated carbon. J Hazard Mater 142:208-215

Liuxue Z, Xiulian W, Peng L, Zhixing S (2007) Photocatalytic activity of anatase thin films coated cotton fibers prepared via a microwave assisted liquid phase deposition process. Surf Coat Tech 201:7607-7614

Mihailović D, Šaponjić Z, Radoičić M, Lazović S, Baily CJ, Jovančić P, Nedeljkovic J, Radetić M (2011) Functionalization of cotton fabrics with corona/air RF plasma and colloidal $\mathrm{TiO}_{2}$ nanoparticles. Cellulose 18:811-825

Mirjalili M, Karimi L, Bararitari A (2015) Investigating the effect of corona treatment on self-cleaning property of finished cotton fabric with nano titanium dioxide. J Text I 106:621-628

Morawski AW, Kusiak-Nejman E, Przepiorski J, Kordala R, Pernak J (2013) Cellulose- $\mathrm{TiO}_{2}$ nanocomposite with enhanced UVVis light absorption. Cellulose 20:1293-1300

Navaneetha Pandiyaraj K, Selvarajan V (2008) Non-thermal plasma treatment for hydrophilicity improvement of grey cotton fabrics. J Mater Process Tech 199:130-139

Ohsaka T, Izumi F, Fujiki Y (1978) Raman spectrum of anatase $\mathrm{TiO}_{2}$. J Raman Spectrosc 7:321-324

Owens DK, Wendt RC (1969) Estimation of the surface free energy of polymers. J Appl Polym Sci 13:1741-1747

Peiro AM, Peral J, Domingo C, Domenech X, Ayllon JA (2001) Low-temperature deposition of $\mathrm{TiO}_{2}$ thin films with photocatalytic activity from colloidal anatase aqueous solutions. Chem Mater 13:2567-2573

Prysiazhnyi V, Kramar A, Dojcinovic B, Zekic A, Obradovic BM, Kuraica MM, Kostic M (2013) Silver incorporation on viscose and cotton fibers after air, nitrogen and oxygen DBD plasma pretreatment. Cellulose 20:315-325

Qi K, Daoud WA, Xin JH, Mak CL, Tang W, Cheung WE (2006) Self-cleaning cotton. J Mater Chem 16:4567-4574

Radetic M (2013) Functionalization of textile materials with $\mathrm{TiO}_{2}$ nanoparticles. J Photochem Photobiol C 16:62-76

Shishoo R (2007) Plasma technologies for textiles. Woodhead Publishing Ltd, Cambridge. ISBN 978-1-84569-073-1

Tung WS, Daoud WA (2011) Self-cleaning fibers via nanotechnology: a virtual reality. J Mater Chem 21:7858-7869

Vigil E, Ayllon JA, Peiro AM, Rodriguez-Clemente R, Domenech X, Peral J (2001) $\mathrm{TiO}_{2}$ layers grown from flowing precursor solutions using microwave heating. Langmuir 17:891-896

Wilson JG, Will GD, Frost RL, Montgomery SA (2002) Efficient microwave hydrothermal preparation of nanocrystalline anatase $\mathrm{TiO}_{2}$ colloids. J Mater Chem 12:1787-1791 
Windler W, Lorenz C, Goetz N, Hungerbuhler K, Amberg M, Heuberger M, Nowack B (2012) Release of titanium dioxide from textiles during washing. Environ Sci Technol 46:8181-8188

Zhang YH, Chan CK, Porter JF, Guo W (1998) Micro-Raman spectroscopic characterization of nanosized $\mathrm{TiO}_{2}$ powders prepared by vapor hydrolysis. J Mater Res 13:2602-2609
Zhang H, Zhu H, Sun R (2012) Fabrication of photocatalytic $\mathrm{TiO}_{2}$ nanoparticle film on PET fabric by hydrothermal method. Text Res J 82:747-754 